\title{
A NEW, ITERATIVE, SYNCHRONOUS-RESPONSE ALGORITHM FOR ANALYZING THE MORTON EFFECT
}

\author{
A Thesis \\ by \\ ROHIT SAHA \\ Submitted to the Office of Graduate Studies of \\ Texas A\&M University \\ in partial fulfillment of the requirements for the degree of \\ MASTER OF SCIENCE
}

December 2010

Major Subject: Mechanical Engineering 


\title{
A NEW, ITERATIVE, SYNCHRONOUS-RESPONSE ALGORITHM \\ FOR ANALYZING THE MORTON EFFECT
}

\author{
A Thesis \\ by \\ ROHIT SAHA
}

Submitted to the Office of Graduate Studies of

Texas A\&M University

in partial fulfillment of the requirements for the degree of

MASTER OF SCIENCE

\begin{abstract}
Approved by:
Chair of Committee, Dara Childs

Committee Members, William Beason

Brian Murphy

Alan Palazzolo

Head of Department, Dennis L. O’Neal
\end{abstract}

December 2010

Major Subject: Mechanical Engineering 


\begin{abstract}
A New, Iterative, Synchronous-Response Algorithm for Analyzing the Morton Effect.

(December 2010)

Rohit Saha, B.Tech., Institute of Technology, Banaras Hindu University

Chair of Advisory Committee: Dr. Dara W Childs
\end{abstract}

The present work proposes a new computational algorithm for analyzing Morton Effect using a Successive Iterative Synchronous Response Algorithm (SISRA). Previous studies on the Morton Effect were based on Eigen or Nyquist analysis for stability studies and predicted only an onset speed of instability. The outcome of SISRA is the convergence of response to a steady state orbit in a finite number of iterations. A progressive increase in the response with increasing running speed indicates the former instability. SISRA predicts both the synchronous response for the speed range of concern plus the speed where the response becomes divergent.

SISRA is implemented in a Timochenko-beam-based finite-element rotordynamics software suite. SISRA analyzes the Morton Effect as a synchronous response problem with excitations from: (1) mechanical imbalance, (2) induced thermal bent shaft moments, and (3) mechanical imbalance that is induced by thermal bow. A general elliptical orbit can be decomposed into the sum of forward and backward circular orbits. As input, SISRA requires that, at a specified speed, equilibrium position, 
and orbit: (1) the predicted maximum differential temperature, and (2) the angle between hot spot (position of maximum temperature) and position of minimum film thickness.

Two examples from the published literature are considered. SISRA predicted higher vibration levels, even before the motion diverges due to Morton Effect. In some cases, the synchronous response of the system due to Morton Effect is orders of magnitude greater than the response due only to mechanical imbalance. The combined effects of: (1) mechanical imbalance with induced thermal bent shaft moments, and (2) mechanical imbalance with thermally induced mechanical imbalance are also studied. The impact of induced thermal bent shaft moments is found to be greater than the mechanical imbalance induced by thermal bow.

A parametric investigation on the impact of the changes of (1) bearing length to diameter ratio, (2) reduced viscosity of the lubricant, (3) bearing radial clearance to radius ratio and (4) overhung mass magnitude is performed to consider their respective impacts on synchronous response. Based on the available input data and the cases considered, reducing viscosity and reducing the overhung mass are found to be the best remedies to alleviate problems arising from the Morton Effect. 


\section{DEDICATION}

To my parents and beloved late grandfathers 


\section{ACKNOWLEDGEMENTS}

I wish to thank my advisor Dr. Dara Childs for giving me an opportunity to work with him. He has been extremely helpful and played a central role in guiding my thesis efforts. The several discussions that I had with him contributed greatly to the progress of my thesis work. Without his help I would not have been able to complete my thesis. His knowledge, guidance and inspiration will always serve as the model of a perfect advisor.

I would also like to thank the other members of my committee, Dr. Alan Palazzolo, Dr. Lynn Beason and Dr. Brian Murphy for their cooperation and suggestions throughout my research. Dr. Brian Murphy deserves special thanks for his insightful comments through discussions, prompt replies to email and providing the model details of his example problem. Many thanks to Mr. Zhenyu Lu and Dr. Alan Palazzolo for helping me out with their bearing code and permission to use them for my thesis.

Special thanks to Mr. Ameen Mohammed, who also helped so much in technical discussions and decoding XLTRC ${ }^{2}$. Many thanks to my friends for all the fun and pleasant stay here in College Station. I owe special thanks to Fareeda Aunty and Shiraz Uncle, for their help, support and parental guidance during the last two years. Finally, my heartfelt appreciation goes to my mother, father and sister for their love and encouragement through my whole life. Without their devotion and care, I could not have accomplished this much. 


\section{TABLE OF CONTENTS}

\section{Page}

ABSTRACT. iii

DEDICATION . $\mathrm{V}$

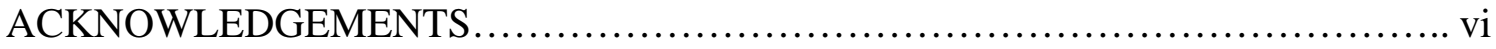

TABLE OF CONTENTS ..................................................... vii

LIST OF FIGURES..................................................... ix

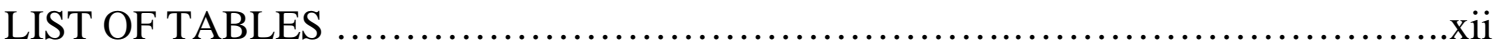

\section{CHAPTER}

I INTRODUCTION ..........................................................

Minimum Film Thickness..................................................5

Newkirk Effect and Morton Effect....................................9

Literature Review..................................................11

Experiments on Morton Effect................................11

Analytical Approaches on Morton Effect.............................14

Case Studies on Morton Effect.........................................21

Research Objective..............................................23

II BACKGROUND AND DEVELOPMENT OF ALGORITHM...................25

III NUMERICAL EXAMPLE...........................................

Model-I, Keogh and Morton (1994): Symmetric Rotor...................36

Influence of the Bearing $L / D$ Ratios...........................45

Influence of the Bearing $C_{r} / R$ Ratios.............................47

Influence of the Overhang Mass..................................49

Influence of the Reduced Lubricant Viscosity.......................51

Model-II, Schmied et al. (2008): Turboexpander.......................52

IV DISCUSSION AND CONCLUSIONS...................................56

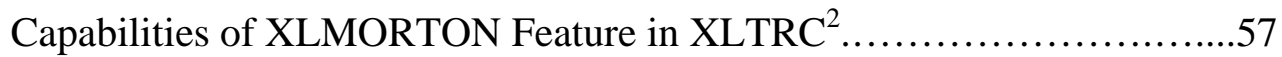

Direction for Future Research..............................................58 
NOMENCLATURE............................................................ 59

REFERENCES........................................................... 62

APPENDIX A CALCULATED DIFFERENTIAL TEMPERATURE AND PHASE ANGLES FOR PLAIN JOURNAL BEARING AT VARIOUS

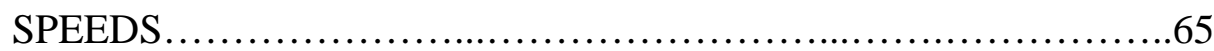

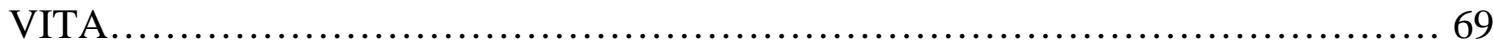




\section{LIST OF FIGURES}

Page

Figure 1 Bent shaft with overhang mass at the right hand side of bearing ......................

Figure 2 Stationary $X, Y$ and rotor fixed $x$ ', $y^{\prime}$ reference system .................................

Figure 3 Decomposition of elliptical orbit into forward and backward precession orbit..4

Figure 4 Forward and backward precessing orbit ...............................................

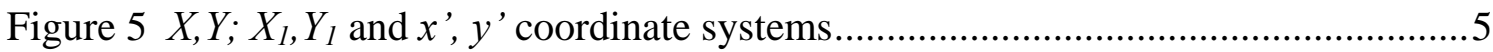

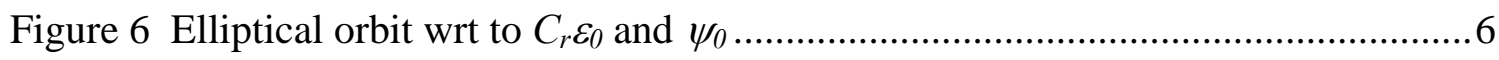

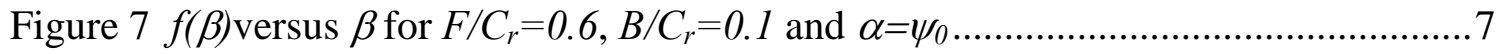

Figure $8 \beta *$ vs $F / B$ ratios for different $\alpha-\psi_{0}$ angles .......................................... 8

Figure 9 Spiral plot of Newkirk Effect[7] .......................................................

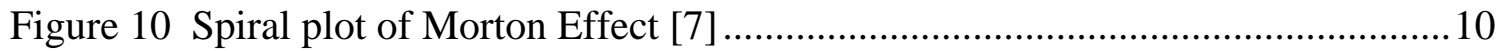

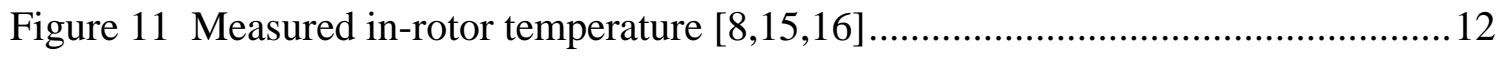

Figure 12 Overhang model by De Jongh and Morton [9] .......................................13

Figure 13 Scheme of instability phenomenon by De Jongh and Morton [9] .................13

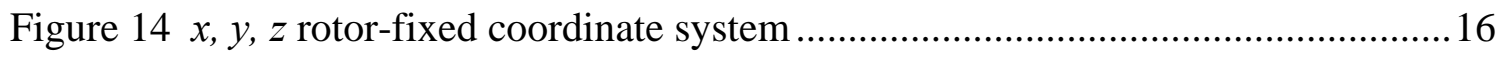

Figure 15 Relative positions of the rotor fixed $x, y, z$ and $x_{T}, y_{T}, z$ coordinate systems ......18

Figure 16 Stability analysis for rotor thermal bend development [11] ........................19

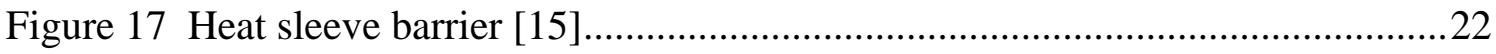

Figure 18 Maximum differential temperature and phase angles for forward and

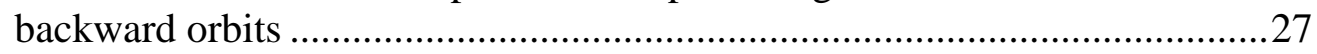

Figure 19 Calculated $\Delta T_{f} / \Delta T_{b}$ and $\varphi_{T f} / \varphi_{T b}$ with different orbit amplitude at $7500 \mathrm{rpm}$ at $\varepsilon_{0}=0.667$ from Table- 2 
Figure 20 Maximum differential temperature and its location wrt different reference

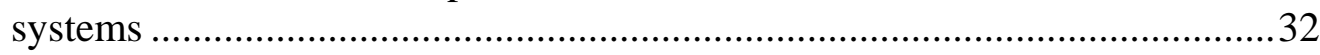

Figure 21 Rotordynamic model of Keogh and Morton [11], symmetric rotor ...............36

Figure 22 First forward critical mode shape .......................................................38

Figure $23 a / C_{r}$ versus iteration number at $9000 \mathrm{rpm}$ at $\varepsilon_{0}=0.659, \psi_{0}=42.5$ representing a steady state and converged solution ........................................................38

Figure $24 a / C_{r}$ versus iteration number at $11000 \mathrm{rpm}$ at $\varepsilon_{0}=0.64$ and $\psi_{0}=43.3^{\circ}$ representing divergent solution 39

Figure 25 Morton Effect response $\rho_{\max }$ with $\omega$ of original model ...............................39

Figure $26 a / C_{r}$ versus $\omega$ with and without Morton Effect of original model .................41

Figure $27 G_{a T}$ verus iteration numbers at $9000 \mathrm{rpm}$ at $\varepsilon_{0}=0.659, \psi_{0}=42.5^{\circ} \ldots \ldots \ldots \ldots \ldots . . . . . .42$

Figure $28 G_{a T}$ verus iteration numbers at $11000 \mathrm{rpm}$ at $\varepsilon_{0}=0.64$ and $\psi_{0}=43.3^{\circ}$

Figure 29 Morton Effect synchronous response with centered imbalance of $50 \mathrm{gm} \mathrm{cm}$ and $100 \mathrm{gm} \mathrm{cm}$.

Figure 30 Bearing reaction versus $\omega$ with and without Morton Effect in $X$ and $Y$

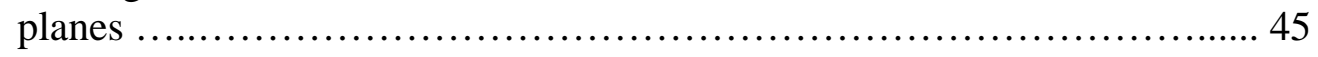

Figure 31 Morton Effect response- $\rho_{\max }$ versus $\omega$ for different $L / D$ ratios ....................46

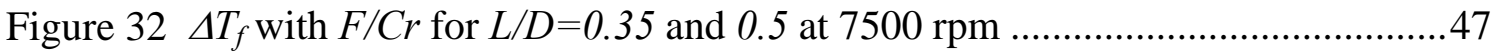

Figure 33 Morton Effect response- $\rho_{\max }$ versus $\omega$ for different $C r / R$ ratios...................48

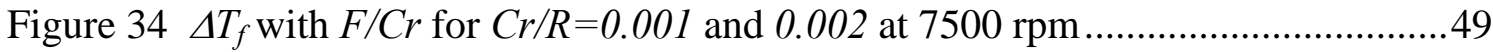

Figure 35 Morton Effect response $\rho_{\max }$ versus $\omega$ for different overhang masses ...........50

Figure 36 Morton Effect synchronous response $a / C r$ versus $\omega$ for different overhung masses. 
Figure 37 Morton Effect response $\rho_{\max }$ versus $\omega$ for different viscosities .....................52

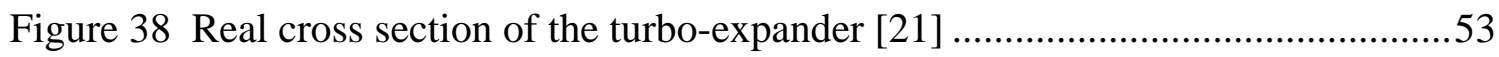

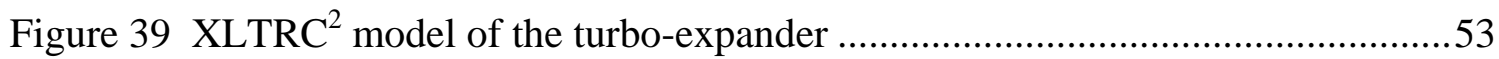

Figure 40 First forward damped critical mode shape of turbo-expander ......................54

Figure 41 Unstable divergent behavior of spiral plot at $18000 \mathrm{rpm}$ [21] ......................54

Figure 42 Morton Effect response $\rho_{\max }$ versus $\omega$ for the compressor and expander

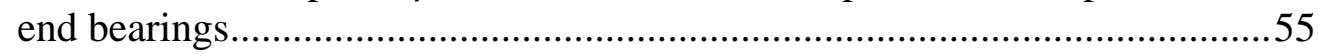




\section{LIST OF TABLES}

Page

Table 1 Comparison of existing analytical approaches on Morton Effect 26

Table 2 Calculated differential temperature and phase angles for forward and backward orbit. 28

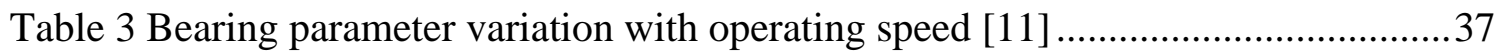

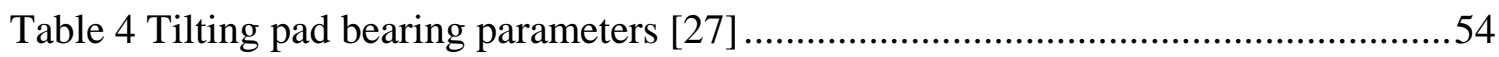

Table A1 Calculated differential temperature and phase angles for $L=0.035 \mathrm{~m}$, $D=0.1 m, C_{r}=100 \mu m$

Table A2 Calculated differential temperature and phase angles for $L=0.05 \mathrm{~m}$, $D=0.1 m, C_{r}=100 \mu m$. .66

Table A3 Calculated differential temperature and phase angles for $L=0.035 \mathrm{~m}$, $D=0.1 m, C_{r}=50 \mu m$. 66

Table A4 Calculated differential temperature and phase angles for $L=0.035 \mathrm{~m}$, $D=0.1 \mathrm{~m}, C_{r}=100 \mu \mathrm{m}$ with overhung mass of $50 \mathrm{~kg}$

Table A5 Calculated differential temperature and phase angles for $L=0.035 \mathrm{~m}$, $D=0.1 m, C_{r}=100 \mu m$ with reduced viscosity.

Table A6 Calculated differential temperature and phase angles for $L=0.055 \mathrm{~m}$, $D=0.09 m, C_{r}=92.5 \mu m$ 


\section{CHAPTER I}

\section{INTRODUCTION}

Synchronous rotor motion implies that the response frequency is at the running speed $\omega$. Synchronous response due to shaft-bow/bent-shaft is common in turbomachinery. Shaft bow can occur due to gravity sag of horizontal rotors, static rotor misalignment [1], hot restart (restart of the machine before the end of thermal transient after the shutdown of machine in operating condition)[1,2], thermal bow, excessive loading and improper shrink fits[1,3]. Imbalance excitation is proportional to $\omega^{2}$ while the bent-shaft excitation is independent of $\omega$. Nicholas et al.[1] first examined the effect of residual shaft bow on the unbalance response of a single mass rotor on a rigid support. Using a transfer-matrix approach, Salamone and Gunter [3] revisited shaft bow synchronous excitation plus the effect of disk skew on the synchronous response of a multi-mass rotor in fluid-film bearing.

The Morton Effect phenomenon is related to differential heating across a hydrodynamic bearing due to a synchronous orbit. When a journal is executing a synchronous orbit around the hydrodynamic bearing center, one portion of the journal surface is at the minimum film thickness, while a diametrically opposite section of the journal surface is at the maximum film thickness. Tighter film thickness areas are generally associated with higher viscous shear stresses, which produce higher temperatures. As a result of this difference in film thickness, a temperature gradient

This thesis follows the style of Journal of Vibration and Acoustics. 
develops across the journal. This temperature gradient causes rotor bending, which creates a slope at the bearing (Figure 1). Equivalent bent shaft moments acting on the rotor at both ends of the bearing can be used to produce this slope. Figure 1 illustrates a bent-shaft due to a temperature difference across the right-hand-side bearing with an overhung mass of mass $m_{g r}$ with its body center at distance $l_{g r}$ to its right of the bearing's center. $\beta_{T}$ is the slope created by the differential temperature. Bent shaft moment $M_{T},-M_{T}$ can be applied at ends of the bearing to produce $\beta_{T}$. These moments are speed independent and provide synchronous excitation to the rotor. Along with induced thermal bent shaft moments, overhung masses like coupling hubs and overhung impellers produce thermally induced mechanical imbalance excitation, due to $\beta_{T}$. Thermally induced mechanical imbalance is proportional to $m_{g_{r}} l_{g r} \beta_{T}$. Thus, Morton Effect causes additional synchronous excitation in the form of bent shaft moments and thermally-induced mechanical imbalance along with the initial rotor mechanical imbalance. When the temperature gradients are large, the synchronous response is high. Sometimes, the response grows rapidly with increasing $\omega$, leading to machine shutdown. Overhung compressors, integrally geared compressors and double-ended drive turbines are specially afflicted by this effect due to heavy overhung mass [4]. 


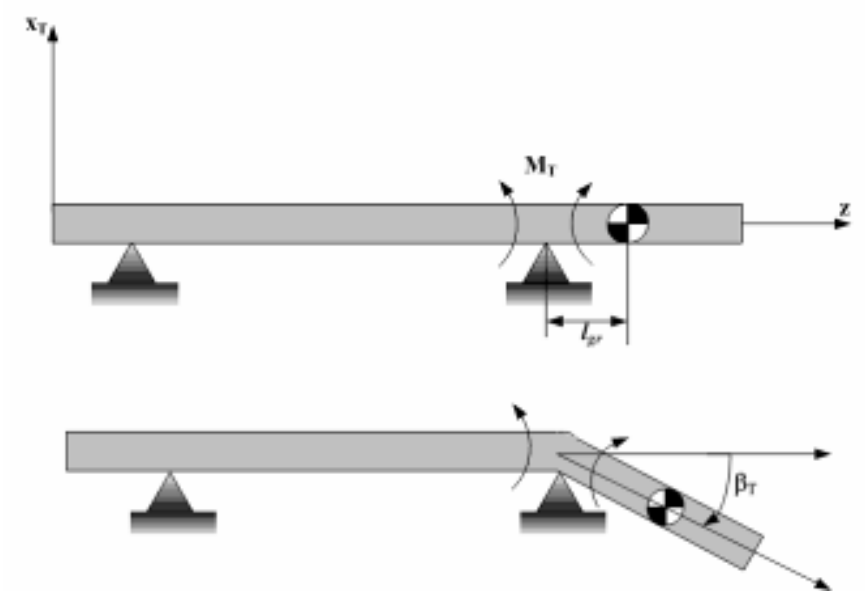

Figure 1. Bent shaft with overhang mass at the right hand side of bearing

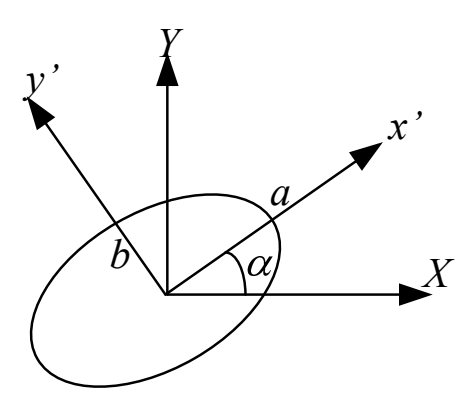

Figure 2. Stationary $X, Y$ and rotor fixed $x$ ', $y^{\prime}$ reference system

As illustrated in Figure 2, the rotor executes a synchronous stationary elliptical orbit in the $X, Y, Z$ reference system. The $x^{\prime}$ and $y^{\prime}$ axes lie along the ellipse principal axes. The angle $\alpha$ is the ellipse attitude angle with major axis $a$ and minor axis $b$. As shown in Figure 3, the elliptical orbit is the sum of a forward and a backward precessing circular orbit. In this paper, positive rotation and positive precession of the rotor is anticlockwise in a forward precessing orbit [see Figure 4(a)]. In a backward precessing orbit, the precession direction of the rotor is clockwise as shown in Figure 4(b). 


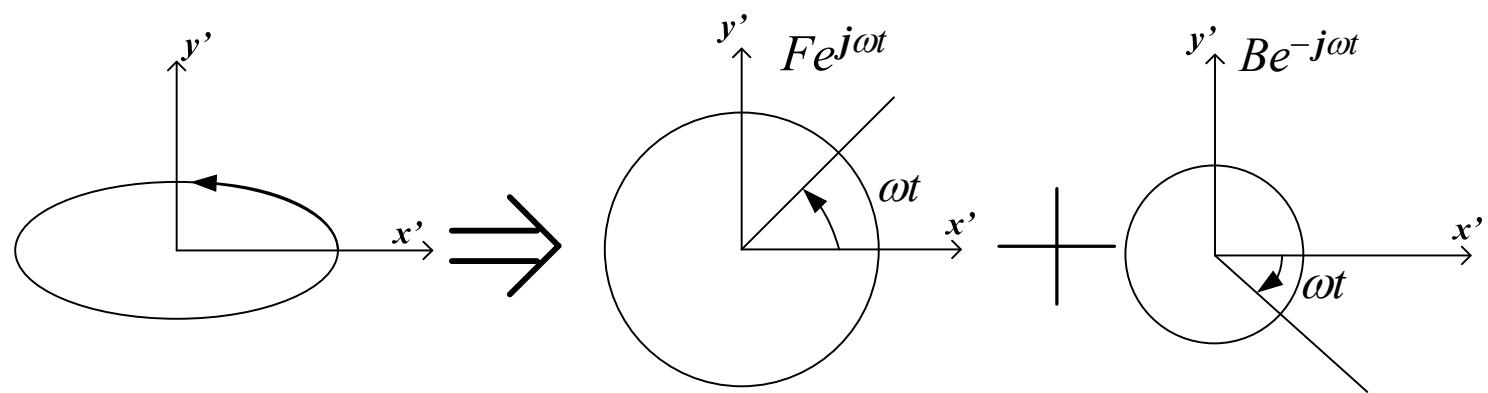

Figure 3. Decomposition of elliptical orbit into forward and backward precession orbit

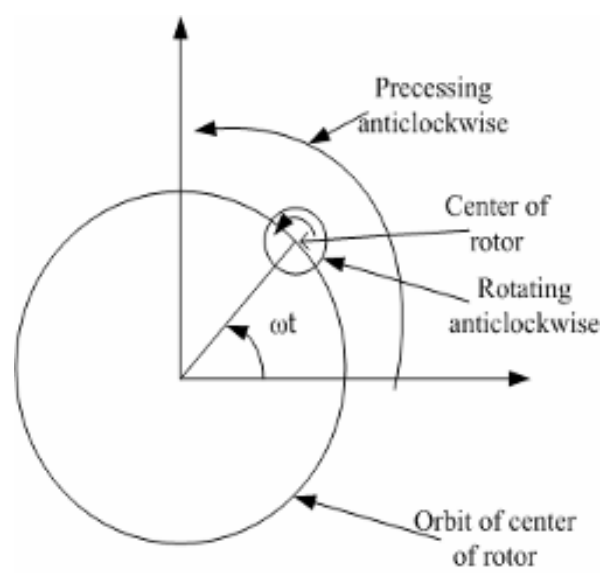

(a)

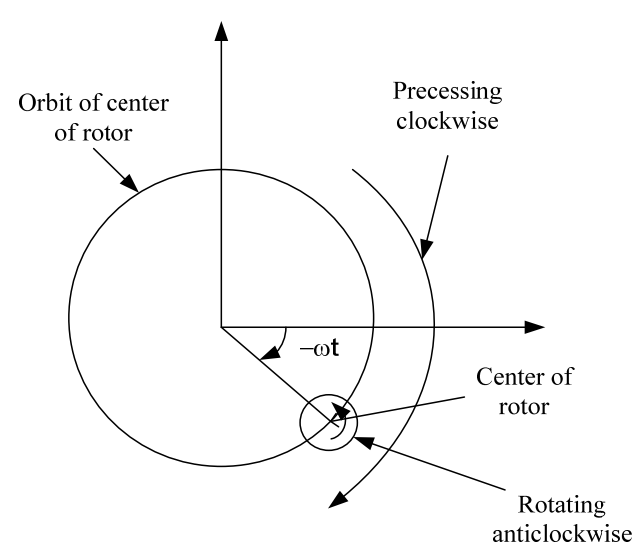

(b)

Figure 4. Forward and backward precessing orbit

The Newkirk Effect arises due to rubbing of rotor and stator results in differential rotor heating, and also causes synchronous vibration. This effect was observed by Newkirk in 1926 [5] as vibrations arising due to rubbing at labyrinth seals. It was clearly modeled and explained by Dimoragonas [6]. Hence, both the Newkirk and Morton Effect produce elevated synchronous excitation due to temperature gradient and can have a spiral behavior; i.e., continuous phase and amplitude of vibration change at constant speed. 


\section{MINIMUM FILM THICKNESS}

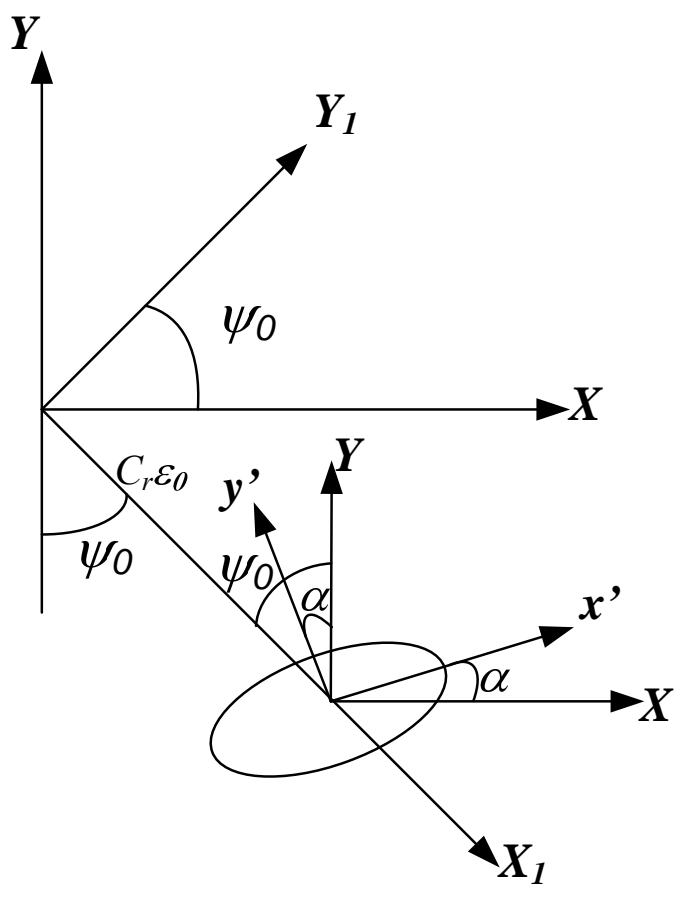

Figure 5. $X, Y ; X_{1}, Y_{1}$ and $x^{\prime}, y^{\prime}$ coordinate systems

For a precessing rotor in a steady state, there exists a location when the journal is closest to the minimum film thickness. The location of the minimum film thickness is a function of forward and backward orbit amplitude $F, B$ (see Figure 3), ellipse attitude angle $\alpha$ (see Figure 2), and static eccentricity $\varepsilon_{0}$ and static attitude angle $\psi_{0}$ (measured in anticlockwise direction from $Y$ axis to the line joining the bearing center to the journal center in static equilibrium). In Figure 5, a coordinate system $X_{1}, Y_{1}$ is set up along the $C_{r} \varepsilon_{0}$ at the angle $\psi_{0}$ with respect to stationary coordinate system $X, Y$. as shown in Figure $6, x^{\prime}, y^{\prime}$ axes are oriented at $\left|\alpha-\psi_{0}\right|$ from the $X_{1} Y_{1}$ axes. 


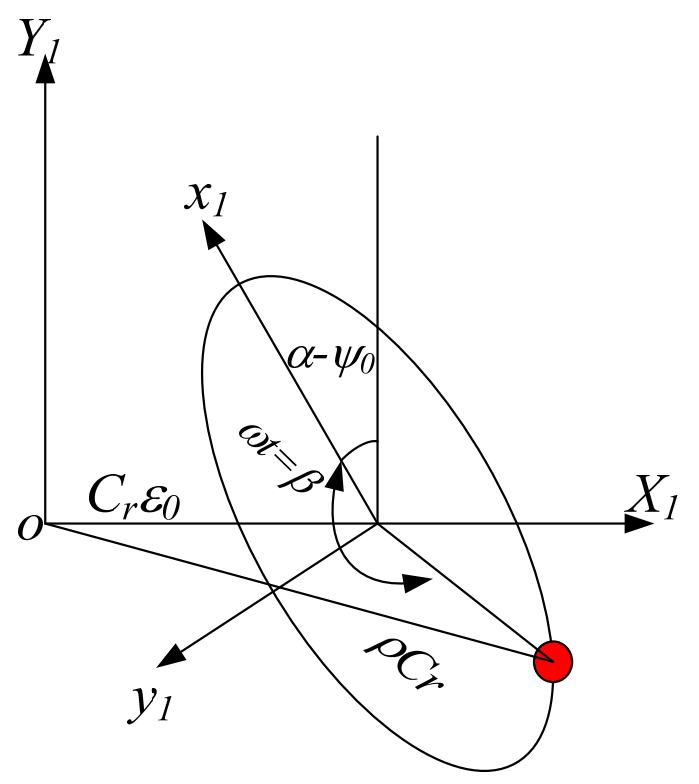

Figure 6. Elliptical orbit wrt to $C_{r} \varepsilon_{0}$ and $\psi_{0}$

The location of the rotor center precessing elliptical orbit $\left(M T_{x}, M T_{y^{\prime}}\right)$ in the $x^{\prime}, y^{\prime}$ coordinate system is

$$
\begin{array}{r}
M T_{x^{\prime}}=F \cos \omega t+B \cos \omega t \\
M T_{y^{\prime}}=F \sin \omega t-B \sin \omega t
\end{array}
$$

The location of the rotor center $\left(M T_{X 1}, M T_{Y 1}\right)$ in the $X_{1}, Y_{1}$ coordinate system is

$$
\begin{aligned}
& M T_{X 1}=C_{r} \varepsilon_{0}-M T_{x^{\prime}} \cos \left(\alpha-\psi_{0}\right)-M T_{y^{\prime}} \sin \left(\alpha-\psi_{0}\right) \\
& M T_{Y 1}=M T_{x^{\prime}} \sin \left(\alpha-\psi_{0}\right)-M T_{y^{\prime}} \cos \left(\alpha-\psi_{0}\right)
\end{aligned}
$$

The film thickness is $C_{r}-\sqrt{M T_{X 1}^{2}+M T_{Y 1}^{2}}$. The film thickness is not constant, it's a function of circumferential location on the journal. For minimum film thickness, $\rho C_{r}=\sqrt{M T_{X 1}^{2}+M T_{Y 1}^{2}}$ should be maximum. After few simplifications, $\rho C r$ can be expressed as 


$$
\begin{aligned}
& C_{r}^{2} \rho^{2}=C_{r}^{2} \varepsilon_{0}^{2}+\left(F^{2}+B^{2}\right)+2 F B \cos 2 \omega t-2 C_{r} \varepsilon_{0} F \sin \left(\omega t+\alpha-\psi_{0}\right)+2 C_{r} \varepsilon_{0} B \sin \left(\omega t-\alpha+\psi_{0}\right) \\
& \rho^{2}=\frac{h^{2}}{C_{r}^{2}}=\varepsilon_{0}^{2}+\left(\left(\frac{F}{C_{r}}\right)^{2}+\left(\frac{B}{C_{r}}\right)^{2}\right)+2 \frac{F B}{C_{r}^{2}} \cos 2 \omega t-2 \varepsilon_{0} \frac{F}{C_{r}} \sin \left(\omega t+\alpha-\psi_{0}\right)+2 C_{r} \varepsilon_{0} \frac{B}{C_{r}} \sin \left(\omega t-\alpha+\psi_{0}\right)
\end{aligned}
$$

Substituting $\omega t=\beta$, and solve for maximum value of $\rho$, to get the position of minimum film thickness $\beta ; \quad \rho \frac{\partial \rho}{\partial \beta}=0$

$$
f(\beta)=2 \sin 2 \beta+\frac{C_{r}}{B} \varepsilon_{0} \cos \left(\beta+\alpha-\psi_{0}\right)-\frac{C_{r}}{F} \varepsilon_{0} \cos \left(\beta-\alpha+\psi_{0}\right)=0
$$

$f(\beta)$ is nonlinear function of $\beta$ and cannot be solved analytically. Thus, bisection method is used to find out the roots of the solution and $\beta *$ are the roots of the equation.

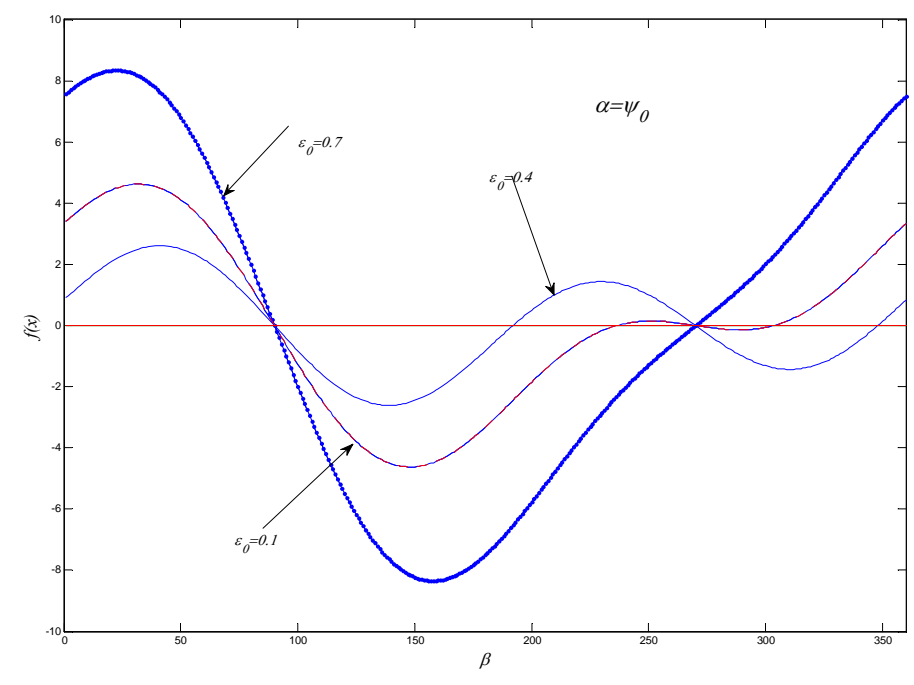

Figure 7. $f(\beta)$ versus $\beta$ for $F / C_{r}=0.6, B / C_{r}=0.1$ and $\alpha=\psi_{0}$

Figure 7 presents $f(\beta)$ versus $\beta$ ( $\beta$ varying from $\left.1-360^{\circ}\right)$ for $F / C_{r}=0.6, B / C_{r}=0.1$, and $\alpha=\psi_{0}$ i.e.; the minor axis of the orbit is along the $X_{1}$ axis for different $\varepsilon_{0}$ values. Multiple roots can exist based on the value of the $F / C_{r}, B / C_{r}, \alpha, \varepsilon_{0}$, and $\psi_{0}$. 


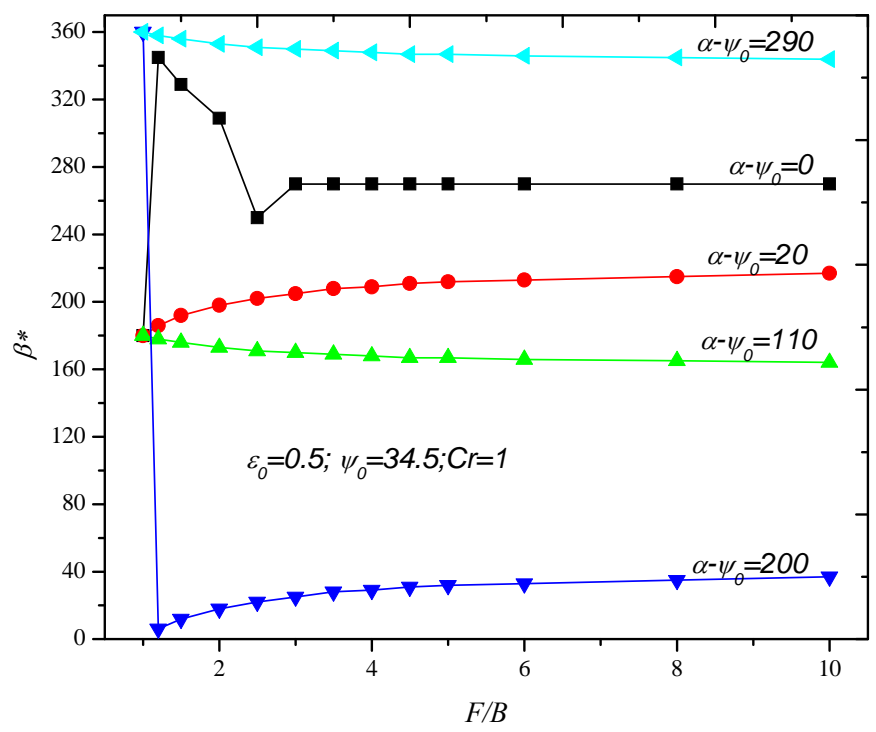

Figure 8. $\beta *$ vs $F / B$ ratios for different $\alpha-\psi_{0}$ angles

In Figure $8, \beta *$ is plotted versus $F / B$ for different $\alpha-\psi_{0}$ values with $\varepsilon_{0}=0.5$. When $F / B=1$, the orbit is a straight line, $\alpha=\psi_{0}, \beta *=0^{\circ}$. For $B=0$, represents a circular orbit, and $\alpha=\psi_{0}, \beta *=270^{\circ}$. Increasing $F / B$ ratio shows the transition from straight line, to elliptical, to circular orbits. For different values of $\alpha-\psi_{0}$, for $F / B>6, \beta *$ does not change.

At $\beta *$, the minimum film thickness should always be greater than zero for the safe operation of the machine from Eq.(3) . In other words, $\rho_{\max }$ must be less than unity; i.e., the rotor must not hit the bearing.

$$
\rho_{\text {max }}=\sqrt{\varepsilon_{0}^{2}+\left(\left(\frac{F}{C_{r}}\right)^{2}+\left(\frac{B}{C_{r}}\right)^{2}\right)+2 \frac{F B}{C_{r}^{2}} \cos 2 \beta^{*}-2 \varepsilon_{0} \frac{F}{C_{r}} \sin \left(\beta^{*}+\alpha-\psi_{0}\right)+2 \varepsilon_{0} \frac{B}{C_{r}} \sin \left(\beta^{*}-\alpha+\psi_{0}\right)}<1
$$


NEWKIRK EFFECT AND MORTON EFFECT

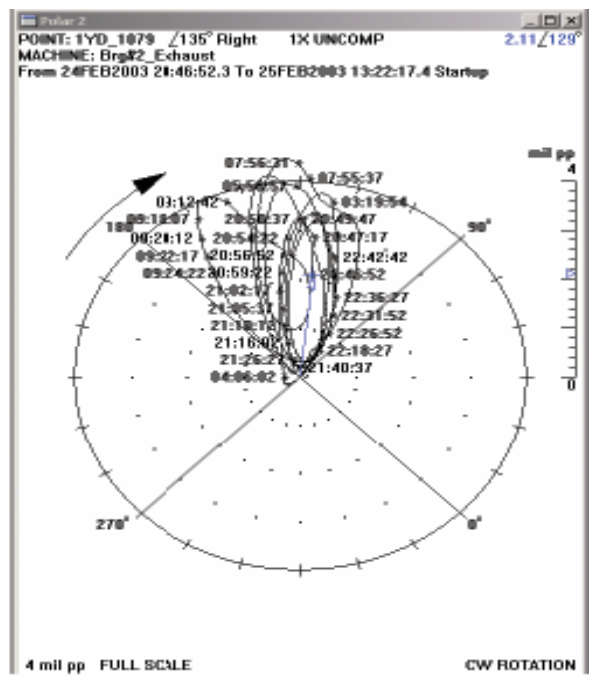

Figure 9. Spiral plot of Newkirk Effect[7]

Phuttipongsit [7] discussed how to distinguish between Newkirk and Morton Effect response from the spiral behavior of their polar plots. Rub is a nonlinear phenomenon that can alter the clearance permanently at the contact location, accompanied by non-repeatable changes of amplitude and phase from one oscillation to another. It may occur both at the bearings and seals. Figure 9 shows the nonlinearity and non-retraceable loops in polar plot of gas turbine response experiencing a light rub. By contrast, the spiral plots of Morton Effect have highly repeatable changes in amplitude and phase during each limit cycle as shown in Figure 10. 


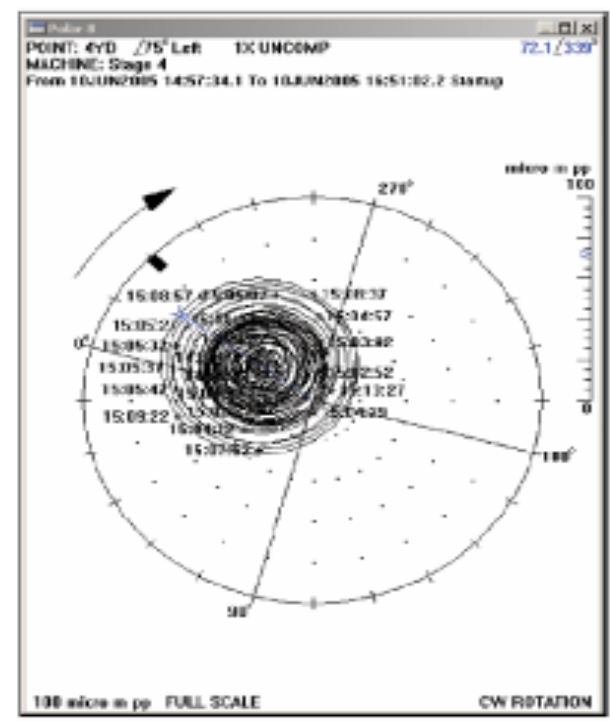

Figure 10. Spiral plot of Morton Effect [7]

The position of highest temperature on the shaft (hot spot) and the position of minimum film thickness coincide in the Newkirk Effect [8]. In the Morton Effect, the hot spot does not coincide with the position of minimum film thickness $[8,9,10]$. Keogh and Morton [11] and De Jongh and Morton [9] predicted that the rotor could have a thermal instability speed zone and can re-stabilize at higher speeds. The Newkirk Effect is insensitive of changes in lubricant flow rate to the bearings and its viscosity, but the Morton Effect is very sensitive to these changes [8,12]. 


\section{LITERATURE REVIEW}

The Morton Effect existed in machines like a disease for a long time, but was never diagnosed for the root cause. This effect was first observed by Paul Morton in the 1970s $[8,13,14]$ as spiral behavior of vibration in power generators with oil lubricated seals. Morton's early experimental investigations on the Morton Effect were published in internal company reports but were not available in the public domain. Unexplained synchronous vibration problems resulting in failures were possibly due to the Morton Effect. An excellent literature overview and review of counter-active measures for the Morton Effect can be found in De Jongh [8].

\section{Experiments on Morton Effect}

De Jongh and Morton [9] experimentally verified divergent synchronous vibration motion in a centrifugal compressor due to differential temperature across the journal in tilting-pad bearing by measuring rotor temperatures at the bearing in a test rig. Their data are the only published in-rotor temperature measurements for hydrodynamic bearings. The experiments were done with a lightly-loaded rotor with a circular forward precessing orbit. They reported temperature difference of $3^{\circ} \mathrm{C}$ for the orbit size of $8 \%$ of the bearing clearance at $10500 \mathrm{rpm}$. They reported an angle between the hot spot and position of minimum film thickness of $20^{\circ}$. They also found that repositioning the 
unbalance mass by an angle of $180^{\circ}$ in the rotor resulted in a change of the location of the hot spot of about the same angle. The in-rotor temperature measurements shown in Figure 11 was reported in subsequent publications by De Jongh $[8,15,16]$. However, the orbit amplitude, eccentricity, running speed, and bearing specifications were not reported for Figure 11. Note they measured angle between the imbalance and the hot spot.

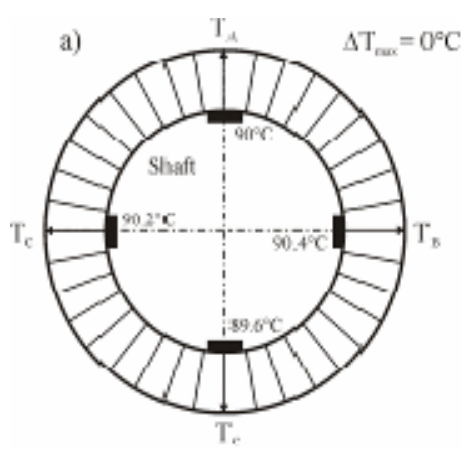

No Imbalance

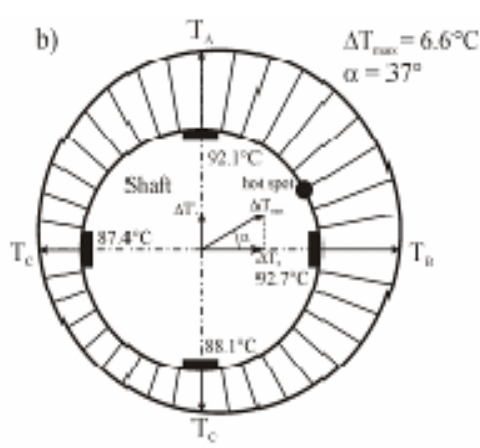

Imbalance at $0^{\circ}$

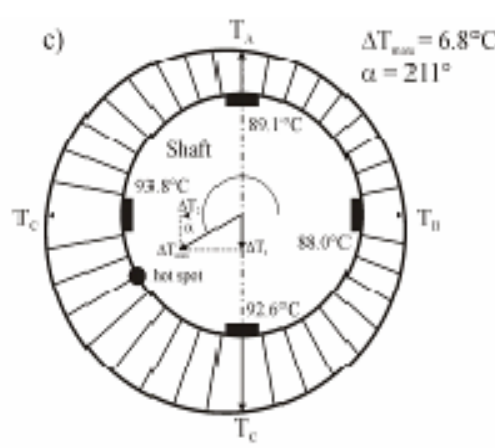

Imbalance at $180^{\circ}$

Figure 11. Measured in-rotor temperature $[8,15,16]$

De Jongh and Morton [9] developed an algorithm based on the temperature measurements to predict synchronous instability. Their rotor model is shown in Figure 12, where $M_{c}$ is the concentrated overhung mass and $l$ is the distance between the overhung mass and the bearing. The angle $\theta$ is the change in the bend angle due to differential temperature at the bearing location. The algorithm is based on the following three transfer functions (refer Figure 13); (1). $M_{c} l$ (overhung moment at the bearing), (2). $\mathbf{I}_{O B}$ (“influence coefficient between the overhung and the bearing location") and depends on the $\omega$, mode shape, system damping and proximity to critical speed and (3). $\boldsymbol{T}(t, \omega)$ (complex thermal gain) is a function $\omega$ and time $t$ and is obtained from experimental 
measurements. The scheme established (shown in Figure 13) defines the gain vector $\boldsymbol{G}$ as the product of three transfer functions. They state that $\operatorname{Re}(\boldsymbol{G})$ should be less than 1 for Morton Effect rotor stability.

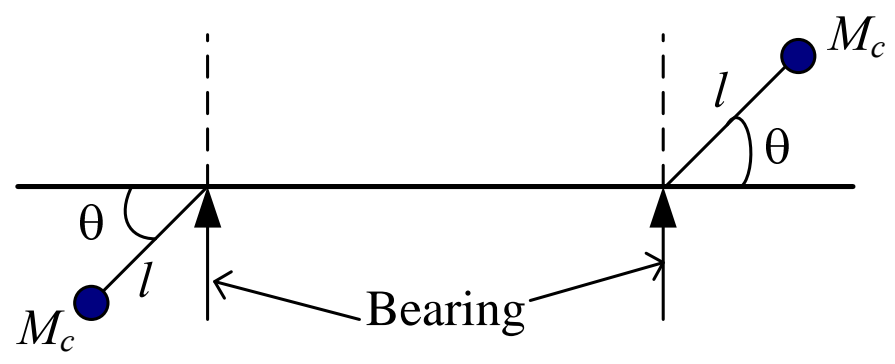

Figure 12. Overhang model by De Jongh and Morton [9]

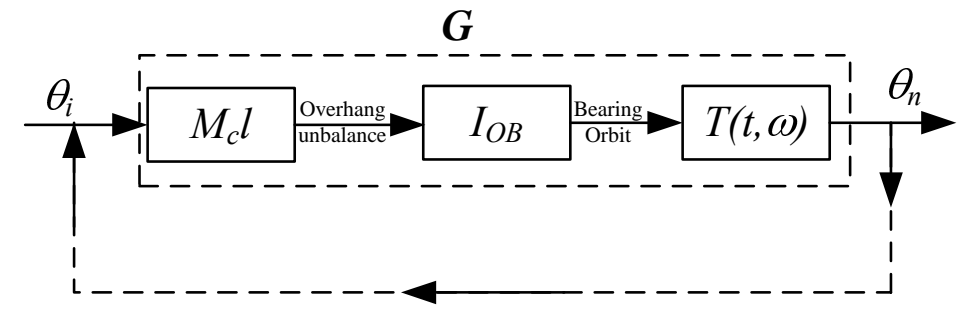

Figure 13. Scheme of instability phenomenon by De Jongh and Morton [9]

In 2008, Morton [13] published some of the results on the differential temperature across the seal from his experiments during 1970s. The results demonstrated a linear trend between orbit size and differential temperature. He found the in-rotor phase angle between the hot spot and the minimum film thickness to be $60^{\circ}$. Note, this phase compares to a measured value of $20^{\circ}$ from De Jongh and Morton [9] for tiltingpad bearings. He reported the differential temperature of $16^{\circ} \mathrm{C}$ for an orbit size of $25 \%$ of the cold radial clearance. 


\section{Analytical Approaches on Morton Effect}

Kellenberger [17] analyzed spiral vibrations in oil lubricated, annular generator shaft seals assuming that the heat input to the shaft came from the rubbing friction, failing to recognize the heating due to shearing of the lubricant. He obtained linear equations by making some simplifying assumptions; e.g., the shaft thermal bow is linearly proportional to the shaft temperature. His model was kinematically incorrect; the correct version of the model was given by Childs [18]. Nonetheless, Kellenberger's model worked well for spiral vibration problems due to rubbing. In addition, he assumed that the ratio of the heat flow into the shaft to the heat flow out of the shaft determined the system stability; i.e., if this ratio was above some threshold curve, then the system would yield unstable spiral vibrations.

Inspired by Kellenberger's work, Schmied [19] investigated spiral vibrations due to hot spots on shafts and gave theoretical evidence of change in rotordynamics behavior due to the bent shaft. He developed and solved a coupled eigenvalue problem of the rotordynamics and thermal equation based on Kellenberger's model. He treated the heat input and the shaft vibration assuming that the heat input was separately proportional to: (i) shaft displacement, (ii) shaft velocity, and (iii) shaft acceleration. Schmied's model has bent shaft excitation, obtained by multiplying the rotor free-free stiffness matrix times the bent-shaft vector, consisting of the displacements and rotations of the shaft with the bent profile. He was the first person to publicly propose spiral vibration as arising due to shearing of lubricant at a bearing. His hot-spot model was incorporated in 
the rotordynamics software MADYN, which he later used to analyze a turbogenerator [20] and a turboexpander [21]. He applied the same hot-spot stability analysis for any rotor system with any heating mechanism (either due to rubbing or viscous shearing). He did not consider the effect of thermally-induced mechanical imbalance.

Based on Kellenberger's [17] and Schmeid's [19] work on spiral vibration, Liebich and Gasch [22] revisited the spiral vibration of the rotor rub problem using modal analysis of coupled thermal/structural equation based on the Kellenberger's model. They suggested relationship between the mode shape and unstable regions from his analysis.

The first analytical investigation of Morton Effect based on the bearing temperature calculation was by Keogh and Morton [14] in 1993. They solved the dynamic energy balance problem for an arbitrarily imposed elliptical orbit on the journal at a plain journal bearing. They used a short-bearing theory with an iso-viscous lubricant and predicted journal temperature for a plain journal bearing with a coolant flow. They showed that forward and backward orbits produce distinctive temperature distribution.

Figure 14 illustrates the $x, y, z$ rotor-fixed coordinate system. The angle $\varphi$ defines the circumferential location of a point on the rotor. Keogh and Morton predicted that a forward synchronous orbit produces a fixed temperature distribution with respect to the rotor; whereas, reverse precession also produces a temperature distribution fixed with respect to the rotor plus an additional reverse-precession temperature distribution that is precessing at twice running speed. They assumed that the rotor thermal rotor response could not respond to a twice running-speed excitation. They also assumed that the 
thermal bend development would be much slower than the rotordynamic response. Inrotor temperature distribution was calculated and incorporated in the rotordynamics model using a bent-shaft excitation similar to Schmied's [19]; using the rotor free-free matrix.

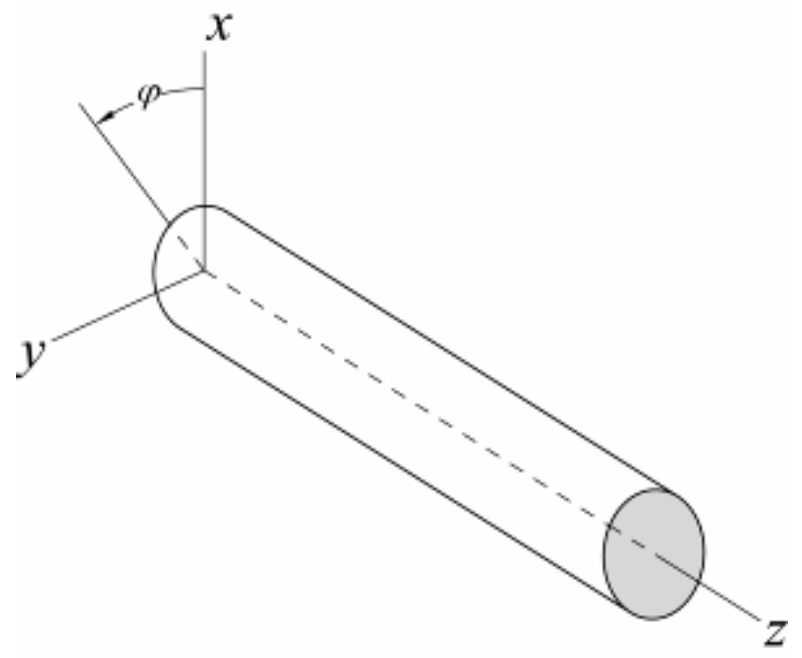

Figure 14. $x, y, z$ rotor-fixed coordinate system

The rotor's orbit at the bearing (see figures 2 and 3) is defined by

$$
\begin{aligned}
\boldsymbol{R}_{0} & =R_{0 X}+\boldsymbol{j} R_{0 Y}=\left(x_{c} \cos \omega t+x_{s} \sin \omega t\right)+\boldsymbol{j}\left(y_{c} \cos \omega t+y_{s} \sin \omega t\right) \\
& =F_{0} e^{j(\omega t+\alpha)}+B_{0} e^{-j(\omega t-\alpha)}=C_{r} \varepsilon_{f} e^{j(\omega t+\alpha)}+C_{r} \varepsilon_{b} e^{-j(\omega t-\alpha)}
\end{aligned}
$$

where, $C_{r}$ is the radial clearance of the bearing. In Eq.(6), $\varepsilon_{f}$ and $\varepsilon_{b}$ are respectively, the ratio of forward and backward precession orbits to $C_{r}$. The major $a$ and minor $b$ ellipse axes (Figure 3) and attitude angle $\alpha$ (Figure 2) are defined by [23]

$$
\begin{aligned}
& a=F_{0}+B_{0} ; b=F_{0}-B_{0} \\
& \alpha=\frac{1}{2} \tan ^{-1}\left(\frac{2\left(x_{s} y_{s}+x_{c} y_{c}\right)}{x_{s}^{2}+x_{c}^{2}-y_{s}^{2}-y_{c}^{2}}\right),
\end{aligned}
$$


where, $a^{2}=\hat{A}+\left(\hat{B}^{2}+\hat{C}^{2}\right)^{\frac{1}{2}} ; b^{2}=\hat{A}-\left(\hat{B}^{2}+\hat{C}^{2}\right)^{\frac{1}{2}} ; \hat{A}=\left(x_{c}^{2}+y_{c}^{2}+x_{s}^{2}+y_{s}^{2}\right) / 2$,

$\hat{B}=\left(x_{c}^{2}+y_{c}^{2}-x_{s}^{2}-y_{s}^{2}\right) / 2 ; \hat{C}=x_{c} x_{s}+y_{c} y_{s}$. Keogh and Morton[14] began with a bent

shaft excitation of statically bent rotor, and calculated the orbit at the bearing location.

For specified $\varepsilon_{f}$ and $\varepsilon_{b}$ values, rotor fixed temperature distributions are calculated and given by

$$
\Delta T_{f}(r, \varphi) ; \Delta T_{b}(r, \varphi)
$$

They assumed a linear radial variation of temperature; i.e., $\Delta T_{j}(r, \varphi)=\Delta T_{j}$, $\Delta T_{j}(r, \varphi \pm \pi)=-\Delta T_{j}$, (where subscript $j$ is either $f$ or $b$, denoting forward and backward orbit, respectively). They calculated a bent shaft angle induced by the linear radial temperature gradient at the bearing using Dimoragonas’ [6] closed-form solution

$$
\boldsymbol{\beta}_{T k}=\beta_{T x}+\mathbf{j} \beta_{T y}=-\mathbf{j} \frac{\gamma_{T}}{I_{a}} \int_{0}^{2 \pi} \int_{0}^{L} \int_{0}^{D / 2} \Delta T_{j}(r, z, \varphi)\left(\frac{D}{2}\right)^{2} e^{j \varphi} d r d \varphi d z
$$

where, $D$ and $L$ are the diameter and length of the bearing, respectively. Further, $\gamma_{T}$ and $I_{a}$ are the coefficient of thermal expansion and area moment of inertia of the journal cross section, respectively.

As illustrated in Figure 1, the hot side of the shaft is at the top of the rotor, and the cold side is at the bottom. The maximum differential temperature lies on the axis oriented with respect to the $x$ axis by $\varphi_{T}$. The relative position of the $x, y$ and $x_{T}, y_{T}$ axes is shown in Figure 15. Keogh and Morton [14] expressed thermal bend as a function of both forward and backward orbit ratios and their respective temperature distributions. 
The net bend angle $\boldsymbol{\beta}_{T k}$ is the sum of the bent angle due to forward $\boldsymbol{\beta}_{T f}$ and backward $\boldsymbol{\beta}_{T b}$ components. Their initial $\boldsymbol{\beta}_{0 k}$ complex bent-shaft angle is due to a statically bent angle at the bearing. Gain $\boldsymbol{G}_{\boldsymbol{1}}$ is defined in terms of the ratio of temperature induced $\boldsymbol{\beta}_{T k}$ and initial $\boldsymbol{\beta}_{0 k}$ complex bent-shaft angles as

$$
\boldsymbol{G}_{1}=\frac{\boldsymbol{\beta}_{T k}}{\boldsymbol{\beta}_{0 k}}
$$

They suggested that $\operatorname{Re}\left(\mathbf{G}_{\mathbf{1}}\right)>1$ indicates unstable growth, and $\operatorname{Re}\left(\mathbf{G}_{\mathbf{1}}\right)<1$ indicates stable decay. Thermally-induced imbalance due to overhang was not considered.

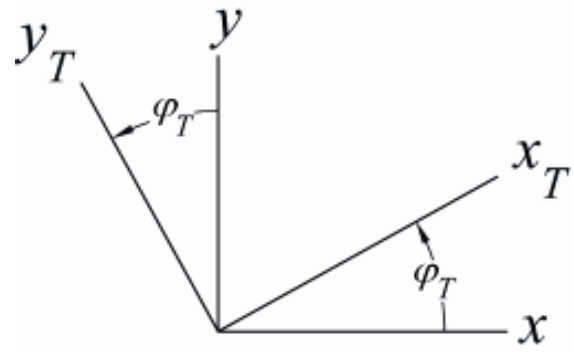

Figure 15. Relative positions of the rotor fixed $x, y, z$ and $x_{T}, y_{T}, z$ coordinate systems

In 1994, Keogh and Morton [11] developed a new analysis starting with timevarying bent-shaft angle components about the body-fixed $x$ and $y$ axes, instead of starting with forward and backward synchronous orbital precession results at the bearing in their earlier publication in 1993[14]. A time-dependent thermal bend was first calculated by combining the heat transfer equations with the dynamic equations of the rotor. This thermal bend was then transformed to the frequency domain where it was incorporated into a positive feedback loop. The stability characteristics of this loop were 
then obtained by plotting Nyquist graphs at successive rotor speeds as shown in Figure 16. They obtained a range of instability speeds for which the real part of the eigenvalues were positive.

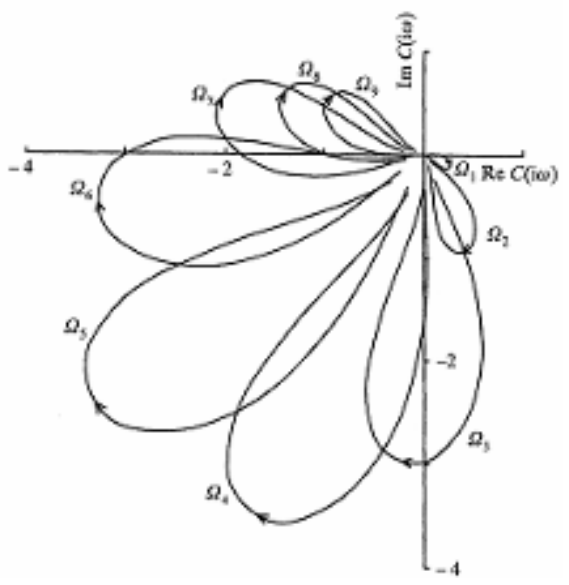

Figure 16. Stability analysis for rotor thermal bend development [11]

Geormiciaga and Keogh [10] used CFD techniques to analyze the dynamic flow and heat transport in the lubricant film in a hydrodynamic bearing and reported that the differential temperature generally increases with speed and orbit size.

Balbahadur and Kirk [24] developed a theoretical model for a synchronous thermal instability caused by differential viscous shearing in the bearings of overhung rotors. The circumferential temperature distribution of the bearing was determined by solving the thermal energy balance equation based on the heat generation rates occurring between the journal, lubricant and bearing. The temperature distribution is used to calculate the thermally induced mechanical imbalance. They calculated the net imbalance as a vector sum of mechanical imbalance (taken as $10 \%$ of total weight of rotor divided by $\omega^{2}$ ) and thermally induced mechanical imbalance. For stability, the net 
imbalance should be less than the threshold imbalance (15\% of the total rotor weight divided by $\omega^{2}$ ). They assumed that the hot spot coincided with minimum film thickness, which contradicts experimental observation made by De Jongh and Morton [9], Morton [13] and predictions by Geomiciaga and Keogh [10]. They validated their approach with case studies for both plain journal and tilting-pad bearings. They did not consider induced bent-shaft excitation or separate contributions due to forward and backward orbits. Currently, some companies are using this method to evaluate Morton Effect in their machines.

Murphy and Lorenz [25] proposed a simplified method for modeling the Morton Effect. They used the following vectors: (1) $\boldsymbol{A}$ (sensitivity of vibration due to mechanical imbalance), (2) $\boldsymbol{B}$ (temperature coefficient vector connecting hot spot on the shaft and position of minimum film thickness), and (3) $\boldsymbol{C}$ (bow coefficient vector, connecting the imbalance vector and the hot spot). For stability, they argue that $[\operatorname{Re}(A B C)]$ should be less than 1 . The temperature difference is found to be linearly proportional to the size of the shaft orbit. This approach calculated the steady state orbit in presence of Morton Effect. However, the input required for the analysis is the temperature profile of the lubricant. 


\section{Case Studies on Morton Effect}

Faulkner et al. [26] encountered the Morton Effect in operating a large turbocharger. The overhung turbine wheel caused a hot spot to develop within the turbine-end bearing. The problem was solved by undercutting the 3-axis groove bearing, thereby increasing the bearing operating eccentricity. The resulting eccentric orbits may have reduced the thermal gradient.

De Jongh and Der Hoeven [15] described the case history of a pipeline compressor with divergent synchronous rotor behavior; due to thermal bend development at one of the bearing journals along with heavy overhung parts. They encountered high synchronous vibration levels with a quick increase in speed. They concluded the root cause of instability was differential temperature across the shaft, generated by the differential shearing of the oil film. They designed a heat sleeve barrier (shown in Figure 17) to reduce the differential heat flow to the shaft and consequently reduce the thermal bending. Installation of the heat sleeve barrier eliminated rotor instability. 


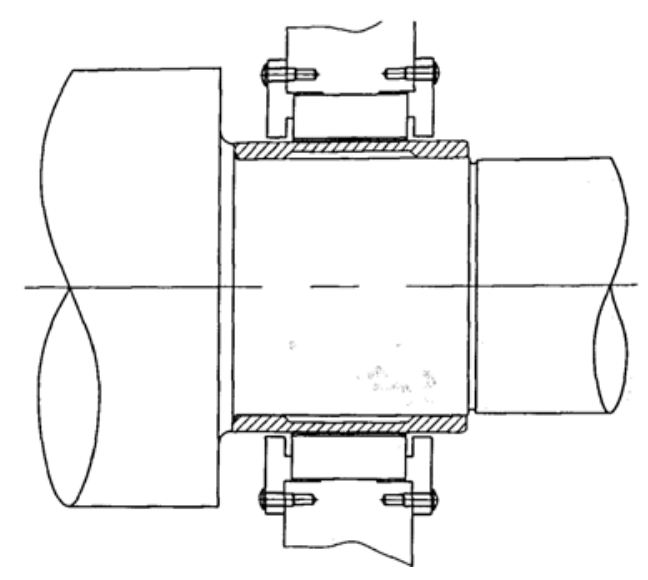

Figure 17. Heat sleeve barrier [15]

Berot and Dourlens [27] suspected Morton Effect instead of Newkirk Effect spiral vibration in overhung centrifugal compressors because the annular seal clearances were too large for rubbing. A compressor was supported by two 5-pad, lightly loaded tilting pad bearings. Inboard bearing was observed to have centered circular orbit. They fixed the synchronous vibration problem by making the orbit elliptic and eccentric, by reducing the $L / D$ ratio of the inboard bearing. Reducing $L / D$, increases the unit load on the bearing which increases the operating eccentricity.

Kocur and De Jongh [16] discussed two Morton Effect case studies involving: (1) Overhung pipeline compressor (single overhung) (2) 30,000 HP gas booster compressor with very heavy coupling. In case (1), a heat sleeve barrier (see Figure 17) was successfully installed, and the compressor ran with no vibration problems. In case (2), a heat sleeve barrier was not applicable because of the high power input to the shaft and installation problems and the problem was fixed by reducing the coupling weight. 
Marscher and Illis [12] reported high synchronous vibration level in an overhung compressor supported on tilting pad bearing due to Morton Effect. They observed with infrared thermography that the temperatures of the bearing pedestals, bearing pads and exit oil temperatures were cyclic. The temperature cycle peaks were not in-phase with each other, nor with the vibration. They fixed the problem by increasing the inlet bearing oil temperature which reduced the lubricant viscosity.

Schmied et al. [21] analyzed a cryogenic turboexpander supported on tilting pad bearings using his hot spot stability analysis (based on [19]). It had a relatively stiff rotor supported on two tilting pad bearings with two overhung impellers. They found the bearings to be the source of hot spot. They fixed the Morton Effect problem by decreasing bearing $L / D$ and reducing the lube oil viscosity.

\section{RESEARCH OBJECTIVE}

According to API 684 [4], "Synchronous thermal rotor instability due to Morton Effect fits the classical definition of an unstable system”. "Classical” rotor stability codes predicting eigen-values, are currently not used to predict its existence. There are also no API analysis requirements for this behavior.

Being motivated by Keogh and Morton [14] and practical experiences from the case studies, the first objective is to develop a rotordynamics analysis that includes all known synchronous excitation. The analysis starts with the calculated temperature 
distributions produced by forward and backward orbits due to mechanical imbalance. The algorithm calculates the steady state synchronous response of the rotor with synchronous excitation arising due to Morton Effect iteratively known as Successively Iterative Synchronous Response Algorithm (SISRA). The second objective is to implement the SISRA in XLTRC ${ }^{2}$ rotordynamics software, to provide a reliable and efficient tool to analyze Morton Effect. 


\section{CHAPTER II}

\section{BACKGROUND AND DEVELOPMENT OF ALGORITHM}

This chapter explains the background and development of the SISRA. This analysis is synchronous, not a stability analysis, as done by earlier investigators $[9,11,19,24,25]$. SISRA includes all the known sources of synchronous excitation arising due to the Morton Effect, namely: (1) Initial mechanical imbalance, (2) thermallyinduced bent shaft moments, and (3) thermally-induced mechanical imbalance due to overhang.

Table 1 shows known Morton Effect aspects and prior analytical approaches that included them in chronological order. The SISRA approach is mostly similar to that of Keogh and Morton [14]. Keogh and Morton [14] and Schmied[19] did not consider thermally induced mechanical imbalance in their calculations. Keogh and Morton used $\boldsymbol{G}_{1}$ to establish system stability, which is a single-step calculation. The present analysis will iteratively calculate the synchronous response at the bearing near the overhang. Keogh and Morton [14] stated that, forward and backward orbits produce separate temperature distribution while Schmied did not consider the influence of forward and backward orbits. Keogh and Morton and Schmied used a bent-shaft excitation vector, that is obtained by multiplying the bent shaft vector (consisting of bent shaft displacements and rotation in $x$ and $y$ planes with the respective rotor free-free stiffness matrix). XLTRC ${ }^{2}$ has a bent-shaft feature (recently modified by the author) which calculates the synchronous response due to bent shaft forces and moments as well as 
bent-shaft-induced imbalance. Balabahadur and Kirk [24] and Murphy and Lorenz [25] considered the effect of thermally induced mechanical imbalance.

Table 1 Comparison of existing analytical approaches on Morton Effect

\begin{tabular}{lcccc}
\hline & {$[11]$} & {$[24]$} & {$[25]$} & Present \\
\hline Induced Thermal Imbalance & $\mathrm{N}$ & $\mathrm{Y}$ & $\mathrm{Y}$ & $\mathrm{Y}$ \\
Bent Shaft Excitation & $\mathrm{Y}$ & $\mathrm{N}$ & $\mathrm{N}$ & $\mathrm{Y}$ \\
$\begin{array}{l}\text { Forward \& Backward Orbits } \\
\text { Phase lag angles between hot }\end{array}$ & $\mathrm{Y}$ & $\mathrm{N}$ & $\mathrm{N}$ & $\mathrm{Y}$ \\
$\begin{array}{l}\text { spot and minimum film } \\
\text { thickness }\end{array}$ & $\mathrm{N}$ & $\mathrm{Y}$ & $\mathrm{Y}$ \\
\hline
\end{tabular}

This algorithm requires as input either measured or calculated maximum differential temperatures with their respective angles between the minimum film thickness and hot spot for forward and backward circular orbits (see Table 2). A parallel research program led by Dr. A. Palazzolo of Texas A\&M University is developing a model and code to predict maximum differential temperature and phase angles for different forward and backward orbit amplitudes [28]. This approach is a 2D finiteelement program to numerically solve coupled variable-viscosity Reynolds, energy and time-transient-heat conduction equations in a fluid film journal bearing to study the transient response of the journal cross section within a revolution based on the principles proposed by [29-31]. Currently, this code is only developed for plain journal bearing. It will be extended for tilting-pad bearings.

For a given equilibrium location of the rotor within a bearing at a specified speed, the table contents (Table 2, input table to XLTRC ${ }^{2}$ at specified speed, static eccentricity and attitude angle) are: (1) $F / C_{r}$ and $B / C_{r}$ are the ratios of forward and 
backward amplitude to radial clearance respectively, (2) $\Delta T_{f}, \Delta T_{b}$ are the maximum differential temperature and (3) $\varphi_{T f}, \varphi_{T b}$ are the phase angles for the forward and backward orbits, respectively. $\Delta T_{f}$ is the maximum differential temperature and $\varphi_{T f}$ is the phase difference measured in anti-clockwise direction (in the direction of forward precession) between the position of minimum film thickness and the hot spot as shown in Figure 18(a) for the forward orbit. Similarly, $\Delta T_{b}$ is the maximum differential temperature and $\varphi_{T b}$ is the phase difference measured in clockwise direction (in the direction of backward precession) between the position of minimum film thickness and the hot spot as shown in Figure 18(b) for the backward orbit. The cold spot (position of minimum temperature) lies diametrically opposite to the hot spot i.e. the differential temperature varies linearly with radius. The location of minimum film thickness is already discussed in the Chapter I.

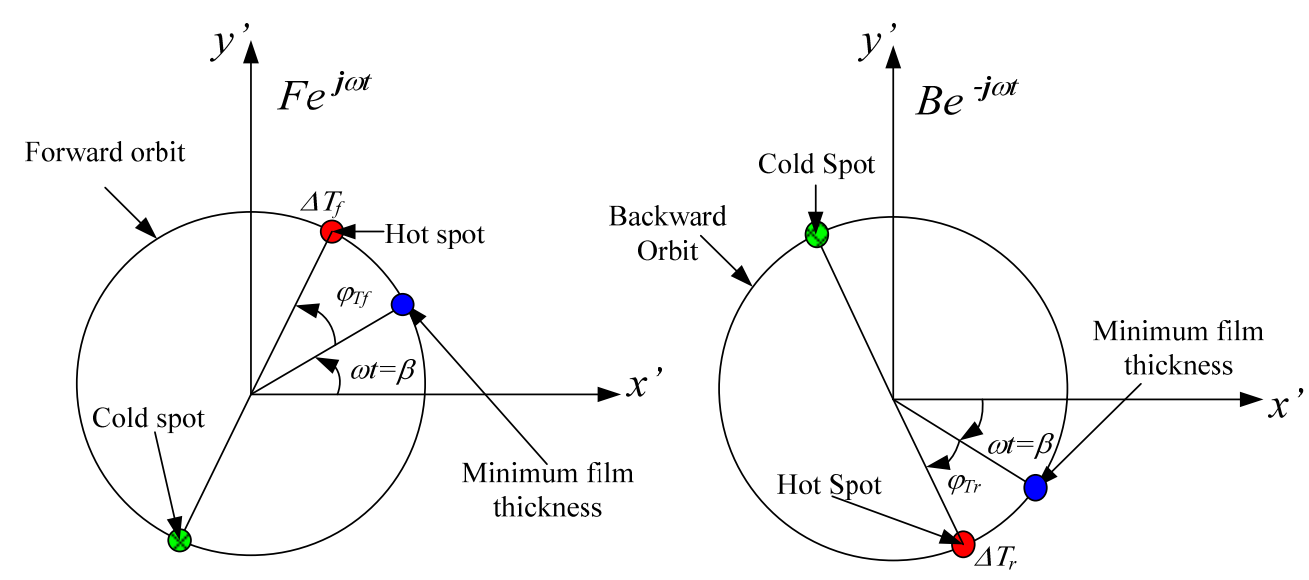

Figure 18 Maximum differential temperature and phase angles for forward and backward orbits 
Table 2 presents calculated differential temperature and phase angles for forward and backward orbits at $\omega=7500 \mathrm{rpm}$ at static eccentricity $\varepsilon_{0}=0.667$, static attitude angle $\psi_{0}=41.2^{0}$ of plain journal bearing with $L=35 \mathrm{~mm}, D=100 \mathrm{~mm}, C_{r}=100 \mu \mathrm{m}, \mu=0.08 \mathrm{~Pa}-\mathrm{s}$.

Table 2 Calculated differential temperature and phase angles for forward and backward orbit

\begin{tabular}{rccccc}
\hline$\frac{F}{C_{r}}$ & $\Delta T_{f}\left({ }^{\circ} \mathrm{C}\right)$ & $\varphi_{T f}$ & $\frac{B}{C_{r}}$ & $\Delta T_{b}\left({ }^{\circ} \mathrm{C}\right)$ & $\varphi_{T b}$ \\
\hline 0.05 & & & & \\
0.10 & 0.7361 & 72 & 0.05 & 0.7898 & -84 \\
0.20 & 2.0314 & 36 & 0.10 & 0.9058 & -48 \\
0.25 & 8.5327 & 24 & 0.20 & 2.1279 & -24 \\
0.30 & 13.785 & 12 & 0.25 & 7.8965 & -12 \\
\hline
\end{tabular}

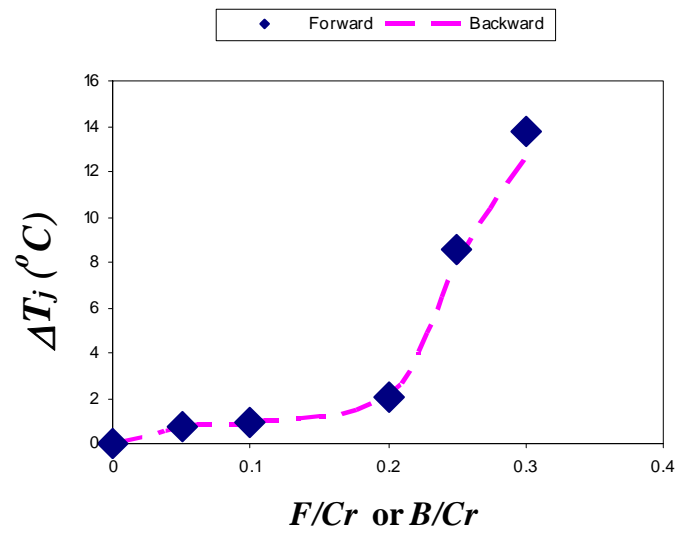

(a)

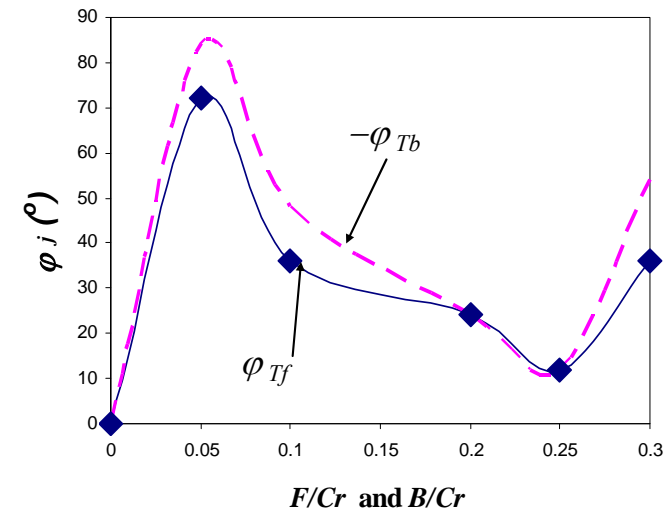

(b)

Figure 19. Calculated $\Delta T_{f} / \Delta T_{b}$ and $\varphi_{T f} / \varphi_{T b}$ with different orbit amplitude at $7500 \mathrm{rpm}$ at $\varepsilon_{0}=0.667$ from Table2

Figure 19(a) and 19(b) show the variation of $\Delta T_{j}$ and $\varphi_{T j}$ for different forward and backward orbit amplitudes, respectively. Note: for small amplitudes, $\Delta T_{j}$ behaves linearly (see $F / C_{r}$ and $B / C_{r}$ upto 0.2 ), but as the orbit size increases, the behavior is nonlinear. $\Delta T_{j}$ shoots up as $\varepsilon_{0}+F / C_{r}$ approaches 1 , i.e., motion approaching the 
clearance. Note, $\Delta T_{f}$ and $\Delta T_{b}$ are approximately same, also predicted by Geormiciaga and Keogh[10] and contradicted by Keogh and Morton[14], where $\Delta T_{b}$ is $40 \%$ less than $\Delta T_{f}$

From Dimoragonas' [6] closed-form solution, the bent angle $\beta_{T}$ due to linear radial temperature differential from Eq. (9) is

$$
\beta_{T}=\Delta T_{1} \frac{\pi \gamma_{T}}{4 I_{a}} L\left(\frac{D}{2}\right)^{3}
$$

where, $\Delta T_{1}$ is the maximum differential temperature. An applied moment $M$ at the end of a cantilevered Euler beam produces the rotation angle $\beta=M L / E I_{a}$. Hence, $\beta_{T}$ can be produced by the following end moment

$$
\beta_{T}=M_{T} L / E I_{a} \Rightarrow M_{T}=\frac{\pi}{4}\left(\frac{D}{2}\right)^{3} E \gamma_{T} \Delta T_{1}=B_{T} \Delta T_{1}
$$

Note, $M_{T}$ is not a function of $L$. Euler Bernoulli and Timoshenko beam theories yield the same rotation angle. Applying $M_{T}$ and $-M_{T}$ moments due to thermal gradient at the right and left hand ends of the bearing produces $\beta_{T}$ (see Figure 1). The signs of $M_{T}$ and $-M_{T}$ correspond to right-hand rotation directions about the $y_{T}$ axis (see Figure 15). With respect to the rotor model, $M_{T}$ and $-M_{T}$ are applied at stations $i^{*}$ and $j^{*}$ corresponding to the station on the left and right hand end of the right bearing, respectively.

The portion of the rotor outside the right-hand side bearing has mass $m_{r b}$, and its mass center lies the distance $l_{g r}$ to the right of the bearing center at station $k^{*}$ in the rotor 
model. For small $\beta_{T}$, thermally induced mechanical imbalance magnitude occurs and has the magnitude given by $m_{r b} l_{\mathrm{g} r} \beta_{T}=C_{T} \Delta T_{1}$

SISRA application for Morton Effect with overhang on the right side for the bearing (refer Figure 1) at a particular speed is described below. The algorithm can also be implemented for overhang on the left side or on both ends.

Step 0a: Calculate the steady-state synchronous response at the bearing due to a positive unit moment at station $i^{*}$ and a negative unit moment at station $j^{*}$; i.e., $M_{i^{*} y}=1$ and $M_{j^{*} y}=-1$ with the remaining bent-shaft forces and moments set to zero. Note: This approach uses the standard full rotor model versus rotor free-free matrices used by $[14,19]$. This step will produce the response vector

$$
\boldsymbol{R}_{1}=\alpha_{1 f} e^{j\left(\omega t+\eta_{1}\right)}+\alpha_{1 b} e^{-j\left(\omega t-\eta_{1}\right)}
$$

Step 0b: Calculate the steady-state synchronous response at the bearing due to a unit imbalance at station $k^{*}$ (locating the center of mass of the overhung rotor segment); i.e., $\left(m_{k^{*}} a_{k^{*}}\right)_{x}=1$ with zero imbalance in the remaining locations. $\left(m_{i} a_{i}\right)_{y}=0$ and $\left(m_{i} a_{i}\right)_{x}=(0,0,0 \ldots \ldots \ldots 1, \ldots .0)$. This step will produce the response vector

$$
\boldsymbol{R}_{2}=\alpha_{2 f} e^{j\left(\omega t+\eta_{2}\right)}+\alpha_{2 b} e^{-j\left(\omega t-\eta_{2}\right)}
$$

Step.0 is the preliminary calculation step, these results are saved, and this step will not be repeated during the iterations at a fixed speed.

Step 1: Calculate synchronous rotor response at the bearing due to the initially specified mechanical imbalance distribution given by 


$$
\begin{aligned}
& \left(m_{i} a_{i}\right)_{x}=\left(m_{1 x} a_{1 x}, m_{2 x} a_{2 x} \ldots \ldots \ldots \ldots \ldots . ., m_{n x} a_{n x}\right) \\
& \left(m_{i} a_{i}\right)_{y}=\left(m_{1 y} a_{1 y}, m_{2 y} a_{2 y} \ldots \ldots \ldots \ldots \ldots . . ., m_{n y} a_{n y}\right)
\end{aligned}
$$

Note: the algorithm could be readily executed to include product of inertia excitations. With the specified mechanical imbalance distribution, the following elliptical orbit at the bearing results

$$
\begin{aligned}
\boldsymbol{R}_{0} & =R_{0 X}+\boldsymbol{j} R_{0 Y}=\left(x_{c} \cos \omega t+x_{s} \sin \omega t\right)+\boldsymbol{j}\left(y_{c} \cos \omega t+y_{s} \sin \omega t\right) \\
& =F_{0} e^{j(\omega t+\alpha)}+B_{0} e^{-\boldsymbol{j}(\omega t-\alpha)}=C_{r} \varepsilon_{f 0} e^{j(\omega t+\alpha)}+C_{r} \varepsilon_{b 0} e^{-j(\omega t-\alpha)}
\end{aligned}
$$

The major and minor ellipse axes $a, b$ and the ellipse attitude angle $\alpha$ can be calculated using Eq. (6).

\section{The iterations will begin from step. 2.}

Step 2: From Step 1, $F_{0} / C_{r}, B_{0} / C_{r}, \alpha_{0}, \beta_{0}, a_{0}$ and $b_{0}$ are produced from the steady state response at the bearing due to the initial mechanical imbalance of Eq. (15). $\beta *$ must be calculated to calculate the effective rotor-fixed temperature distribution for every orbit (using Eq. (4)). Based on $F_{0} / C_{r}$ and $B_{0} / C_{r}$ as input for the Table 2, $\Delta T_{f}, \Delta T_{b}, \varphi_{T f}$, and $\varphi_{T b}$ are obtained by interpolation, from the input Table. 2. Using the interpolated values of $\Delta T_{f}, \Delta T_{b}, \varphi_{T f}$ and $\varphi_{T b}$, the rotor-fixed temperature distribution due to forward and backward orbit temperature distribution is

$$
\Delta T_{1} e^{j \varphi}=\left(\Delta T_{f} \cos \left(\beta^{*}+\varphi_{T f}\right)+\Delta T_{b} \cos \left(\beta^{*}+\varphi_{T b}\right)\right)+\boldsymbol{j}\left(\Delta T_{f} \sin \left(\beta^{*}+\varphi_{T f}\right)-\Delta T_{b} \sin \left(\beta^{*}+\varphi_{T b}\right)\right)
$$

The resultant maximum differential temperature $\Delta T_{1}$ and its location $\varphi_{T}$ with respect to the $x, y, z$ (refer Figure 20) is 


$$
\begin{aligned}
& \Delta T_{1}=\sqrt{\Delta T_{f}^{2}+\Delta T_{b}^{2}+2 \Delta T_{f} \Delta T_{b} \cos \left(2 \beta^{*}+\varphi_{T f}+\varphi_{T b}\right)} \\
& \varphi_{T}=\tan ^{-1}\left(\frac{\Delta T_{f} \sin \left(\beta^{*}+\varphi_{T f}\right)-\Delta T_{b} \sin \left(\beta^{*}+\varphi_{T b}\right)}{\Delta T_{f} \cos \left(\beta^{*}+\varphi_{T f}\right)+\Delta T_{b} \cos \left(\beta^{*}+\varphi_{T b}\right)}\right)
\end{aligned}
$$

Note: when $270^{\circ}>\left(2 \beta^{*}+\varphi_{T f}+\varphi_{T b}\right) \geq 90^{\circ}$ the effect of the vector sum of the forward and backward temperature contribution on the effective temperature is subtractive. The minimum temperature is located at $\varphi_{T} \pm \pi$. The steps below must be updated to include forward and backward precession contributions and use $\varphi_{T}$ to locate the peak temperature.

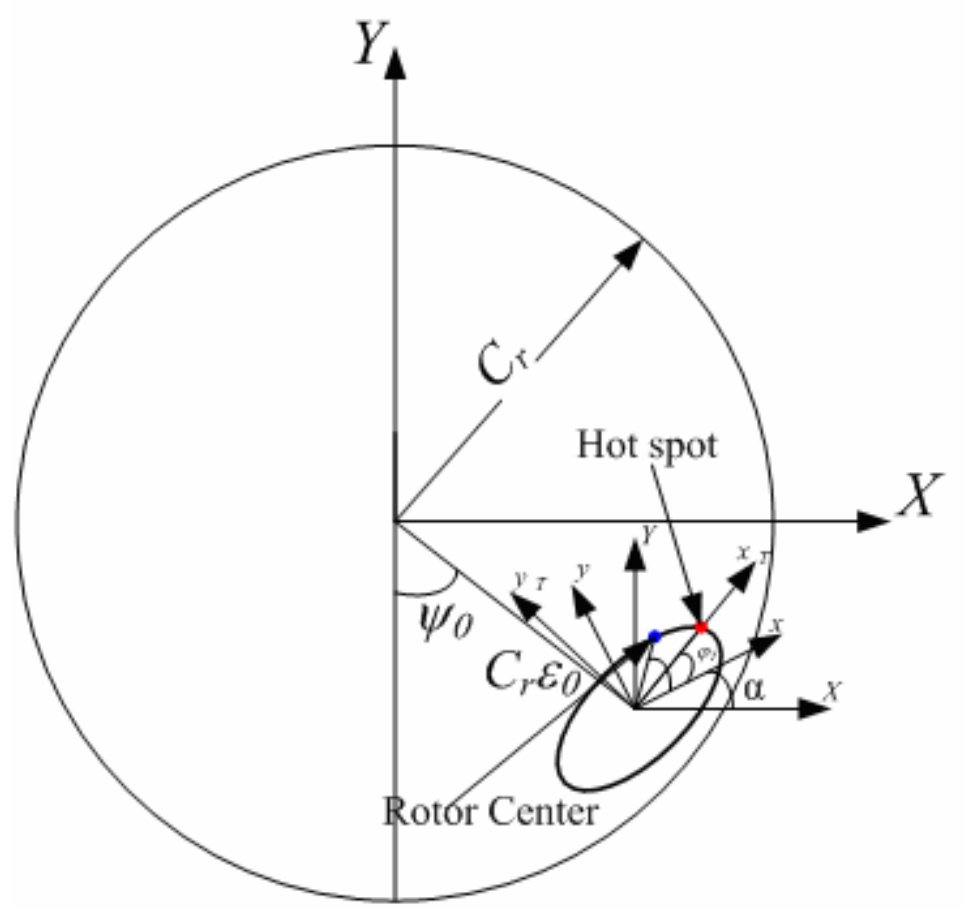

Figure 20. Maximum differential temperature and its location wrt different reference systems

Step 3a: Calculated moment magnitudes related to $\Delta T_{1}$ 


$$
M_{T}=\frac{\pi}{4}\left(\frac{D}{2}\right)^{3} E \gamma_{T} \Delta T_{1}=B_{T} \Delta T_{1}
$$

The resulting synchronous excitation due to bent shaft moments $M_{T,-} M_{T}$ in the rotor-fixed $x_{T}, y_{T}$ and $z$ coordinate system is

$$
\begin{aligned}
& \left(M_{T}\right)_{x_{T}}^{T}=0 \\
& \left(M_{T}\right)_{y_{T}}^{T}=\Delta T_{1} B_{T}(0,0 \ldots . .1,0,-1, . .)
\end{aligned}
$$

The bent-shaft moment components in the $x, y, z$ system are:

$$
\begin{aligned}
& \left(M_{T, x}\right)^{T}=-\Delta T_{1} B_{T}(0,0, \ldots \ldots-1,0,1, \ldots) \sin \varphi_{T} \\
& \left(M_{T, y}\right)^{T}=\Delta T_{1} B_{T}(0,0, \ldots \ldots-1,0,1, \ldots) \cos \varphi_{T}
\end{aligned}
$$

From Step 0a, the corresponding synchronous response at the bearing due to this bent-shaft moment distribution in stationary coordinate system $X, Y, Z$ is

$$
\Delta T_{1} B_{T}\left[\alpha_{1 f} e^{j\left(\omega t+\eta_{1}\right)}+\alpha_{1 b} e^{-j\left(\omega t-\eta_{1}\right)}\right] \times e^{j\left(\pi / 2+\varphi_{T}\right)}=\Delta T_{1} B_{T}\left(\alpha_{1 f} e^{j\left(\omega t+\eta_{1}-\varphi_{T}\right)}+\alpha_{1 b} e^{-j\left(\omega t-\eta_{1}+\varphi_{T}\right)}\right)
$$

Step 3b: Calculate the thermally-induced mechanical imbalance and resultant synchronous response due to $\Delta T_{1}$. The induced imbalance magnitude (mass times displacement) is $C_{T} \Delta T_{1}$. In the rotor-fixed $x_{T}, y_{T}, z$ coordinate system, the imbalance excitation vectors are

$$
\left(f_{T, x_{T}}\right)_{i}^{T}=-\Delta T_{1} C_{T} \omega^{2}(0,0, \ldots \ldots . \ldots . . .) ;\left(f_{T, y_{T}}\right)_{i}^{T}=0,
$$

where, the non-zero entry is at station $k^{*}$, the station for the mass center of the overhung mass in Figure 1. The negative sign arises because (see Figure 1), the induced imbalance 
vector is in the $-x_{T}$ direction. In the reference rotor fixed $x, y, z$ system, the temperatureinduced-imbalance excitation vectors are given by

$$
\begin{aligned}
& \left(f_{T, x}\right)_{i}^{T}=-\Delta T_{1} C_{T} \omega^{2}(0,0 \ldots \ldots . . \ldots) \cos \varphi_{T} \\
& \left(f_{T, y}\right)_{i}^{T}=-\Delta T_{1} C_{T} \omega^{2}(0,0 \ldots \ldots 1, \ldots) \sin \varphi_{T}
\end{aligned}
$$

From Step 0b, the synchronous response at the bearing due to unit induced imbalance distribution in stationary coordinate system $X, Y, Z$ is

$$
-C_{T} \Delta T_{1} \omega^{2}\left(\alpha_{2 f} e^{j\left(\omega t+\eta_{2}\right)}+\alpha_{2 b} e^{-j\left(\omega t-\eta_{2}\right)}\right) e^{j\left(\pi / 2-\varphi_{T}\right)}=-C_{T} \Delta T_{1} \omega^{2}\left(\alpha_{2 f} e^{j\left(\omega t+\eta_{2}+\varphi_{T}\right)}+\alpha_{2 b} e^{-j\left(\omega t-\eta_{2}-\varphi_{T}\right)}\right)
$$

Step 5: Recalculate the synchronous response at bearing $j$ by combining the calculated effects of: (i) The mechanical imbalance distribution, (ii) the induced bent shaft moments due to bent-shaft excitation, and (iii) the thermally induced mechanical imbalance vector due to bent-shaft excitation. Summing these results, the forwardprecessing synchronous response is

$$
F_{1} e^{j\left(\omega t+\chi_{1}\right)}=F_{0} e^{j(\omega t+\alpha)}+\Delta T_{1} B_{T} \alpha_{1 f} e^{j\left(\omega t+\eta_{1}-\varphi_{T}\right)}-C_{T} \Delta T_{1} \omega^{2} \alpha_{2 f} e^{j\left(\omega t+\eta_{2}+\varphi_{T}\right)}
$$

Similarly, the backward-precessing synchronous response is

$$
B_{1} e^{-j\left(\omega t-\chi_{1}\right)}=B_{0} e^{-j(\omega t-\alpha)}+\Delta T_{1} B_{T} \alpha_{1 b} e^{-j\left(\omega t-\eta_{1}+\varphi_{T}\right)}-C_{T} \Delta T_{1} \omega^{2} \alpha_{2 b} e^{-j\left(\omega t-\eta_{2}-\varphi_{T}\right)}
$$

\section{This is end of $1^{\text {st }}$ iteration.}

At the end of each iteration step, the total gain factor $G_{a T}$

$$
G_{a T}=\frac{F_{i}+B_{i}}{F_{i-1}+B_{i-1}}
$$

is calculated where, $F_{i}$ and $B_{i}$ are forward and backward amplitudes, respectively at the end of $i^{\text {th }}$ iteration. $G_{a T}$ is a real number, not complex. $\left(G_{a T}-1\right)$ is checked to see if it is 
less than tolerance (0.001 in the code); if yes, the steady state converged solution is obtained. Otherwise, $\Delta T_{f}, \Delta T_{b}, \varphi_{T f}$, and $\varphi_{T b}$ are calculated from the input table using the new $F_{i} / C_{r}$ and $B_{i} / C_{r}$ at end of each iteration, and calculate new peak differential temperature $\Delta T_{1}$ and location $\varphi_{T}$ from Eq. (8).

Steps 2 to 4 are repeated until convergence or termination of the code. The code will terminate if location of rotor orbit crosses the clearance circle i.e., $\rho_{\max }=\sqrt{\varepsilon_{0}^{2}+\left(\left(\frac{F}{C_{r}}\right)^{2}+\left(\frac{B}{C_{r}}\right)^{2}\right)+2 \frac{F B}{C_{r}^{2}} \cos 2 \beta^{*}-2 \varepsilon_{0} \frac{F}{C_{r}} \sin \left(\beta^{*}+\alpha-\psi_{0}\right)+2 \varepsilon_{0} \frac{B}{C_{r}} \sin \left(\beta^{*}-\alpha+\psi_{0}\right)}<$ 1. $\rho_{\max } \geq 1$, indicates the divergence of the motion due to Morton Effect, and the speed at which $\rho_{\max }$ exceeds 1 , is the divergent Morton Effect speed. 


\section{CHAPTER III}

\section{NUMERICAL EXAMPLE}

This chapter presents numerical examples for two example models from the published literature and discusses the results and some conventional practices that have been used to eliminate Morton Effect problem.

\section{MODEL-I, KEOGH AND MORTON (1994): SYMMETRIC ROTOR}

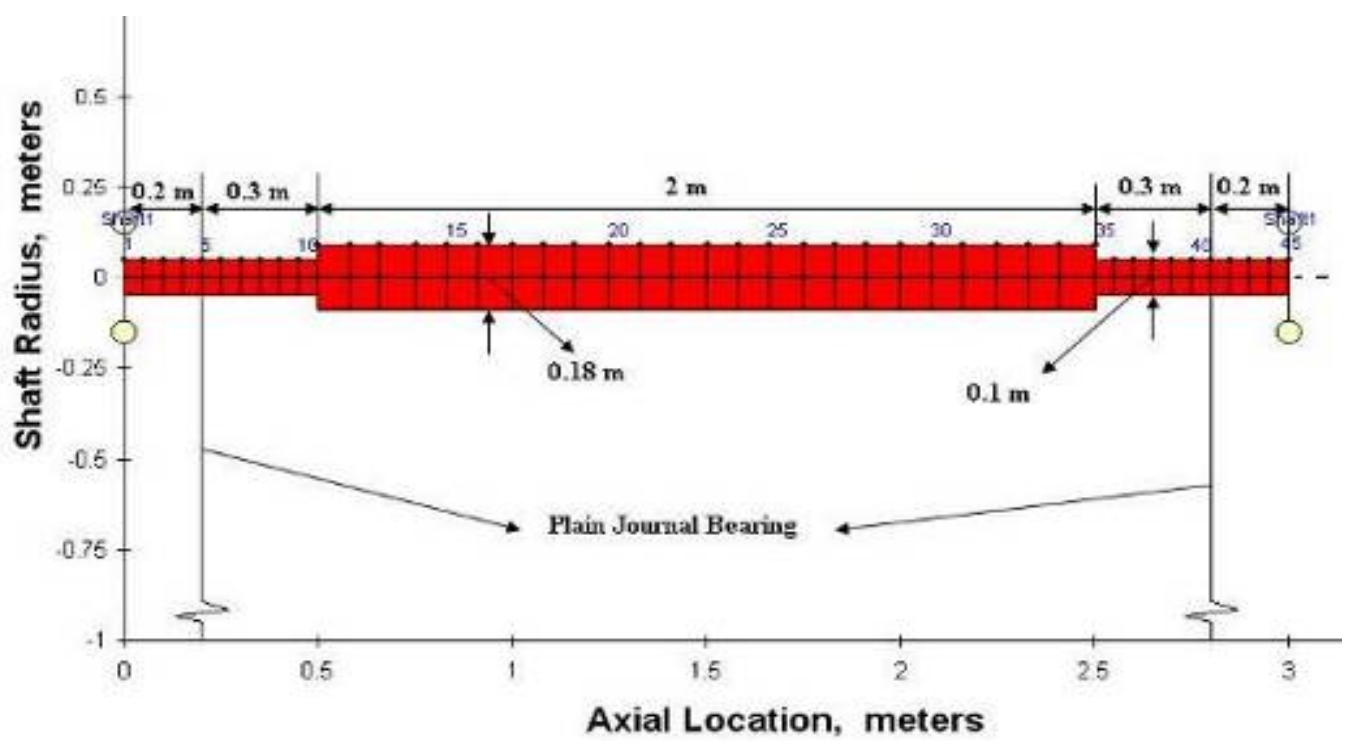

Figure 21. Rotordynamic model of Keogh and Morton [11], symmetric rotor

The rotordynamics model shown in Figure 21 is a symmetric flexible rotor with end mounted discs (each with mass $20 \mathrm{~kg}$ ), supported by two identical plain journal bearing from Keogh and Morton [11]. This model will be the base model of the study. The model is discretized into 44 beam elements. The bearings are at stations 5 and 41 . 
For the bearing, $L=35 \mathrm{~mm}, D=100 \mathrm{~mm}, C_{r}=100 \mu \mathrm{m}$ and $\gamma_{T}=1.1 \mathrm{e}^{-5} /{ }^{0} \mathrm{C}$. The steady state operating eccentricity, attitude angle, viscosity with running speed of the rotor bearing is given in Table. 3 from [11]. The stiffness and damping coefficients of the plain journal bearings are calculated using the short-bearing approximation [23] because the $L / D$ ratio is 0.35 . The rotor's first and second critical speed is around 4000 and $7000 \mathrm{rpm}$, respectively. The first forward damped mode is a cylindrical rigid-body mode (shown in Figure 22). Only right-bearing results are presented because of symmetry. Assuming, the maximum continuous operating speed is $6000 \mathrm{rpm}$; the maximum mechanical imbalance according to API 684[4] is approximately $50 \mathrm{gm}-\mathrm{cm}$ and is at the rotor's mid-span. The differential and phase angles are given in Table A1 from [28].

Table 3 Bearing parameter variation with operating speed [11]

\begin{tabular}{cccc}
\hline $\begin{array}{c}\text { Operating Speed } \\
\omega(\mathrm{rad} / \mathrm{s})\end{array}$ & $\begin{array}{c}\text { Viscocity } \\
\mu(\mathrm{N} / \mathrm{m} / \mathrm{s})\end{array}$ & $\begin{array}{c}\text { Eccentricity ratio } \\
\varepsilon_{0}\end{array}$ & $\begin{array}{c}\text { Attitude Angle } \\
\psi_{0}\end{array}$ \\
\hline 4772.73 & 0.0893 & 0.709 & 38 \\
5727.27 & 0.0873 & 0.686 & 39.8 \\
6681.82 & 0.0824 & 0.672 & 40.9 \\
7636.36 & 0.0775 & 0.662 & 41.7 \\
8590.91 & 0.0716 & 0.655 & 42.2 \\
9545.46 & 0.0677 & 0.648 & 42.7 \\
10500.00 & 0.0638 & 0.642 & 43.2 \\
11454.55 & 0.0598 & 0.638 & 43.5 \\
\hline
\end{tabular}




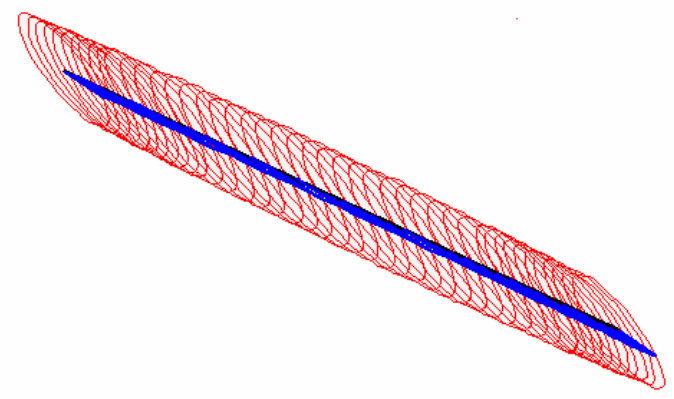

Figure 22. First forward critical mode shape

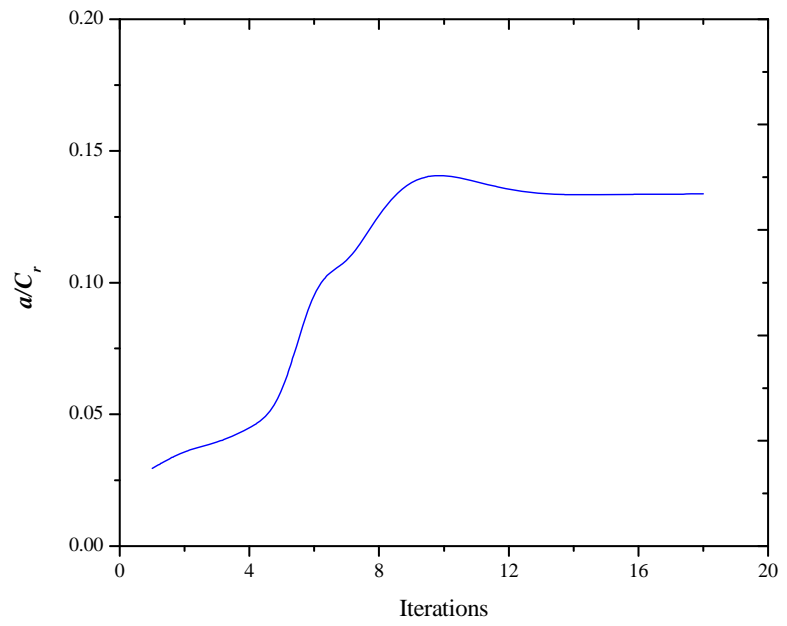

Figure 23. $a / C_{r}$ versus iteration number at $9000 \mathrm{rpm}$ at $\varepsilon_{0}=0.659, \psi_{0}=42.5$ representing a steady state and converged solution

Figure 23 illustrates the convergence characteristic of $a / C_{r}$ versus iteration numbers. For $\omega=9000 \mathrm{rpm}$ with $\varepsilon_{0}=0.659$ and $\psi_{0}=42.5^{\circ}$, the algorithm converges to a steady state response in less than 20 iterations (200 is the maximum numbers of iterations in the code). The convergence characteristics of $b / C_{r}, \beta *$, and $\alpha$ versus iteration number are similar. 


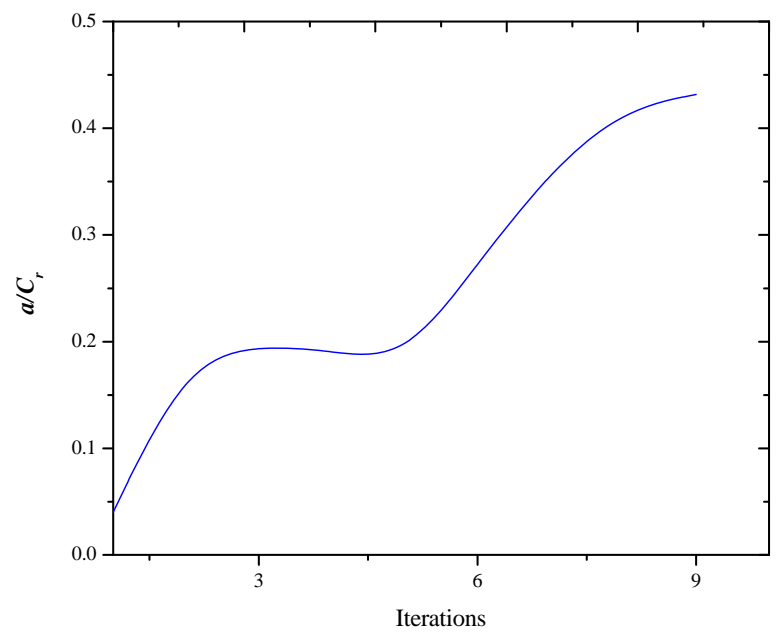

Figure 24. $a / C_{r}$ versus iteration number at $11000 \mathrm{rpm}$ at $\varepsilon_{0}=0.64$ and $\psi_{0}=43.3^{\circ}$ representing divergent solution

Figure 24 illustrates a case at $\omega=11000 \mathrm{rpm}$ with $\varepsilon_{0}=0.64$ and $\psi_{0}=43.3^{\circ}$, when the amplitude grows unboundedly indicating diverging behavior. In this case, $\rho_{\max }$ will approach the 1 . The convergence characteristic of $b$ with iterations is similar.

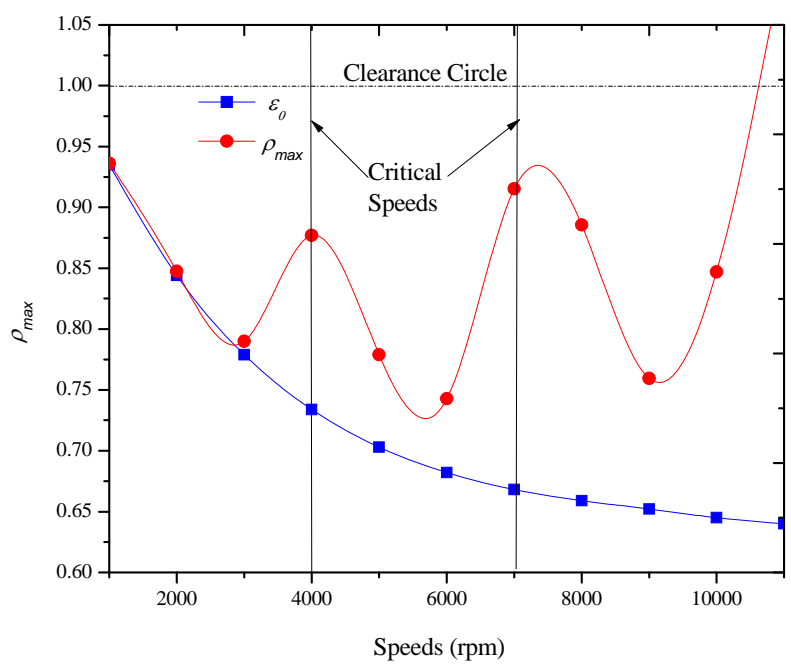

Figure 25. Morton Effect response $\rho_{\max }$ with $\omega$ of original model 
Figure 25 presents $\rho_{\max }$ versus $\omega$ for the original model with full Morton Effect and initial mechanical imbalance. Full Morton Effect has synchronous excitations from induced bent shaft moments and thermally-induced mechanical imbalance. At speeds beyond $10000 \mathrm{rpm}, \rho_{\max }$ exceeds the clearance circle, i.e., the response diverges. Below this speed, a steady state converged solution is obtained. The distinct peaks at 4000 and $7000 \mathrm{rpm}$ in the response are the first and the second critical speeds. Operation near a critical speed may not cause the response to diverge but it may produce higher levels of synchronous vibration. $\Delta T$ increases with increases in orbit amplitude. Near a critical speed, the higher amplitudes result in higher $\Delta T$ s, which causes higher synchronous excitation due to Morton Effect.

Keogh and Morton [11] calculated an instability zone between 9769 rpm and 10371 rpm. Balbahadur and Kirk [32] predicted the resultant imbalance exceeding threshold imbalance between $10001 \mathrm{rpm}$ to $11521 \mathrm{rpm}$. SISRA predicts the diverging motion at speeds approximately near $11000 \mathrm{rpm}$ and does not predict recovery at higher speeds. There may be zone of recovery depending on the system configuration. Recovery can happens when, $270^{\circ}>\left(2 \beta^{*}+\varphi_{T f}+\varphi_{T b}\right) \geq 90^{\circ}$. In such cases, adding temperature contribution due to forward and backward orbits reduces the effective differential temperature. De Jongh and Morton [9] observed recovery in Morton Effect instability at higher speeds.

Figure 26 presents $a / C_{r}$ versus $\omega$ with full Morton Effect and mechanical imbalance and without Morton Effect (only mechanical imbalance). Full Morton Effect 
with mechanical imbalance response is significantly different from the synchronous response of the system due only to mechanical imbalance after $2000 \mathrm{rpm}$.

This figure also shows synchronous response due to induced bent shaft moments and mechanical imbalance (i.e. full Morton Effect without thermally induced mechanical imbalance) is dominating the response. Response due to mechanical imbalance and thermally induced bent shaft moments causes the response to diverge at $11000 \mathrm{rpm}$.

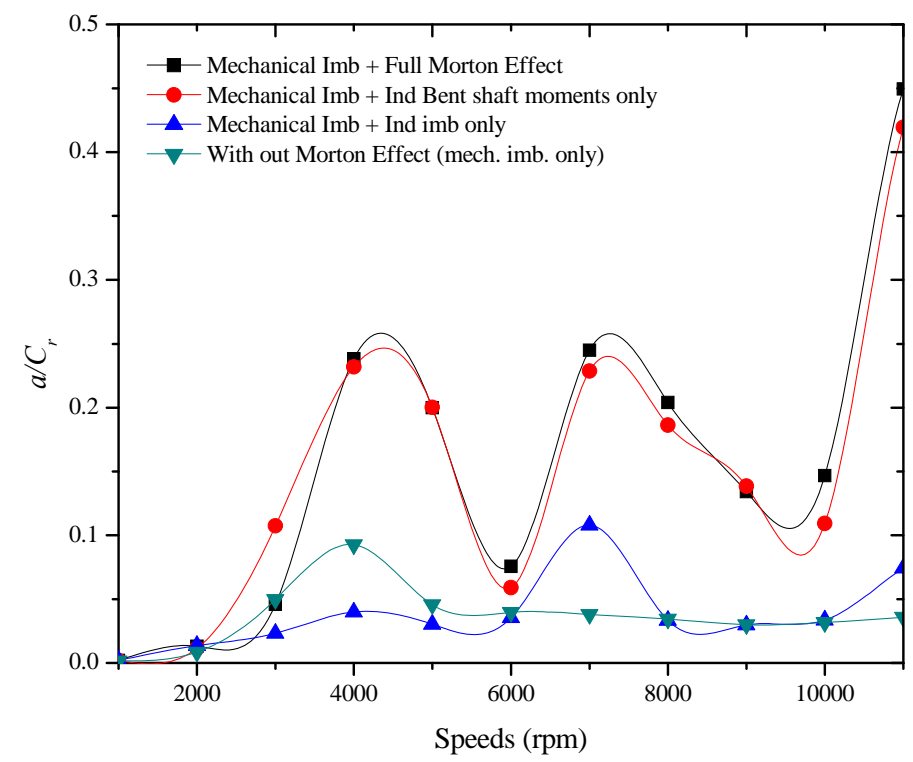

Figure 26. $a / C_{r}$ versus $\omega$ with and without Morton Effect of original model

This figure also compares synchronous response predictions with only thermallyinduced mechanical imbalance and mechanical imbalance. As discussed in Chapter II, the thermally induced mechanical imbalance acts at the mass center of the overhung part (refer Figure 1). The thermally-induced mechanical imbalance at the overhangs excites motion around the second critical speed. Balbahadur and Kirk [32] calculated only the 
magnitude of induced imbalance, and also predicted that at threshold speed, magnitude of thermally-induced imbalance is less that the mechanical imbalance.

Figure 27 shows $G_{a T}$ versus iteration numbers at $\omega=9000 \mathrm{rpm}$ at $\varepsilon_{0}=0.659$ and $\psi_{0}=42.5^{\circ}$. The dotted line shows a convergence $G_{a T}=1$. This condition represents the steady state and convergent solution condition.

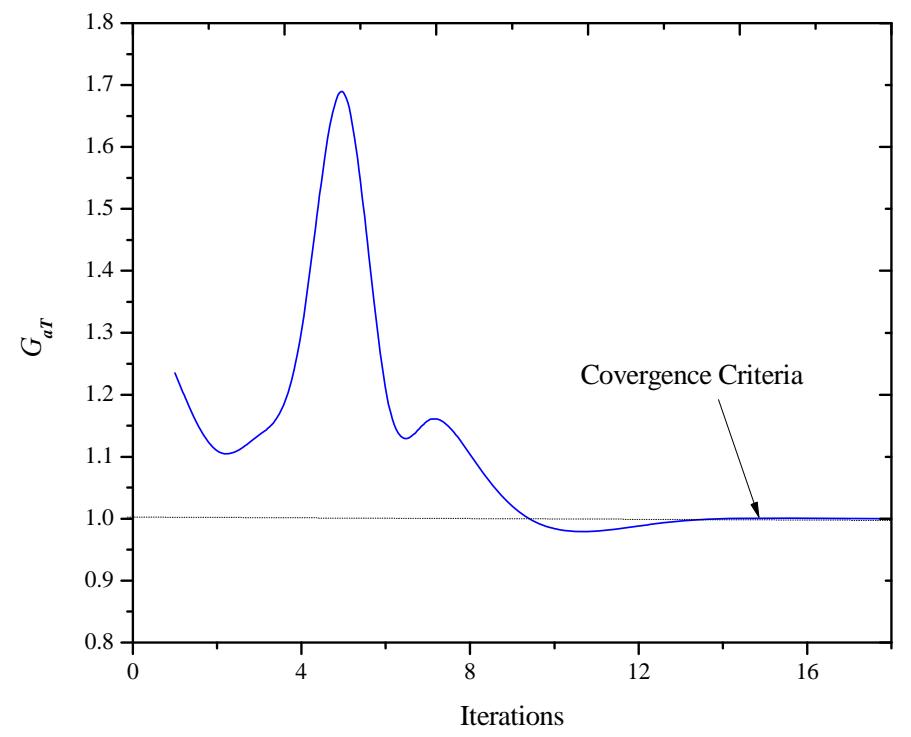

Figure 27. $G_{a T}$ verus iteration numbers at $9000 \mathrm{rpm}$ at $\varepsilon_{0}=0.659, \psi_{0}=42.5^{\circ}$

Figure 28 shows $G_{a T}$ versus iteration numbers at $\omega=11000 \mathrm{rpm}$ at $\varepsilon_{0}=0.64$ and $\psi_{0}=43.3^{\circ}$. This condition represents the divergent solution condition. The code terminated prior to convergence because response grows, and $\rho_{\max }$ exceeds 1.

Hence, $G_{a T}$ may indicate divergent rotor motion due to the Morton Effect when there is no convergence. $G_{a T}$ is analogous to $\operatorname{Re}\left(\boldsymbol{G}_{\mathbf{1}}\right)>1$ by Keogh and Morton[14], 
$\operatorname{Re}(\boldsymbol{G})>1$ used by De Jongh and Morton [9] and the $\operatorname{Re}(\boldsymbol{A B C})>1$ by Murphy and Lorenz[25]. Notice, the $G_{a T}$ is the ratio of amplitudes i.e., real number not complex.

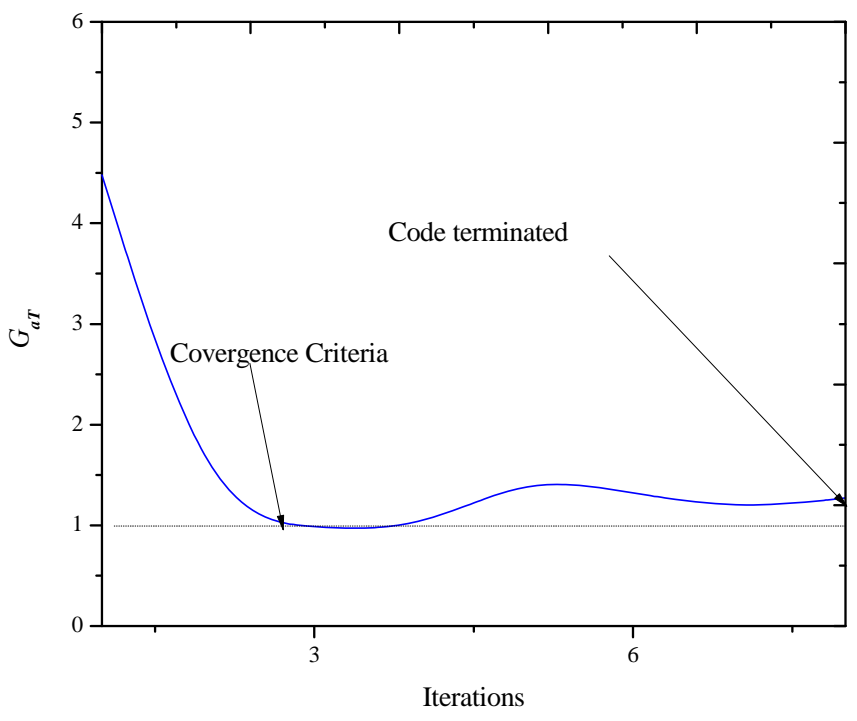

Figure 28. $G_{a T}$ verus iteration numbers at $11000 \mathrm{rpm}$ at $\varepsilon_{0}=0.64$ and $\psi_{0}=43.3^{\circ}$

The bearing synchronous response calculation is linear; however, calculations of forward $F$ amplitude and backward $G$ amplitude, ellipse attitude angle $\alpha$ and the location of minimum film thickness from the bearing response are nonlinear. Addition of the inrotor temperatures due to forward and backward orbits is also nonlinear. The fact that the system converges after multiple steps (instead of one step) also suggests a nonlinear character for the calculation underlying the difference between the linear nature of analysis proposed by earlier investigators $[9,11,14,24,25]$ and the present approach. 


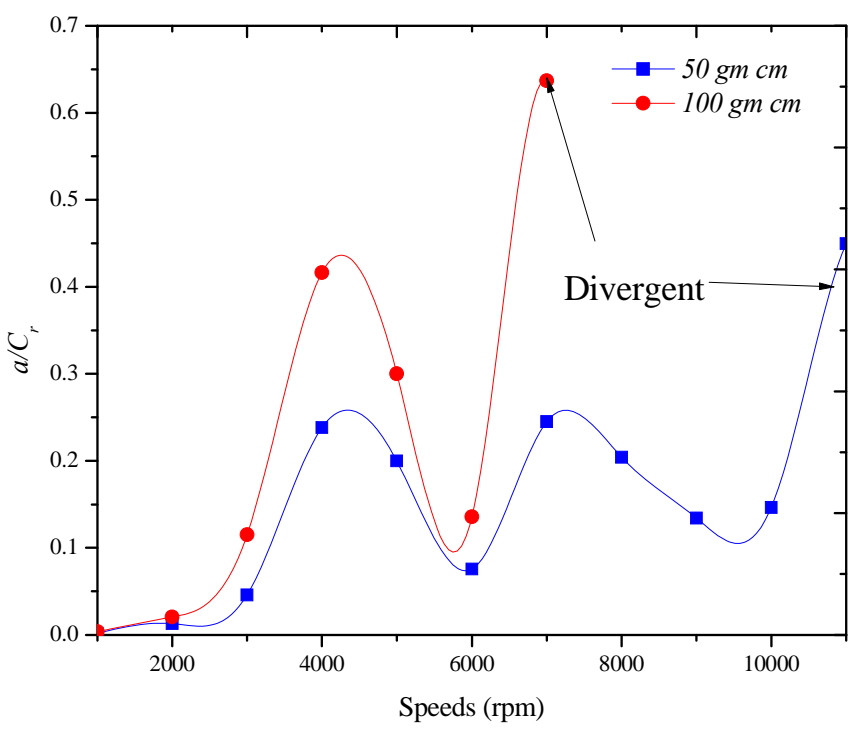

Figure 29. Morton Effect synchronous response with centered imbalance of $50 \mathrm{gm} \mathrm{cm}$ and $100 \mathrm{gm} \mathrm{cm}$

Figure 29 shows significant change in the Morton Effect synchronous response with different mechanical imbalance magnitudes at the mid-span at $0^{\circ}$ in the rotor. Larger mechanical imbalance causes larger orbit amplitude which drives the larger differential temperature in the bearing, which in turn provides higher synchronous excitations due to Morton Effect. Divergent speeds due to Morton Effect are 7000 rpm for $100 \mathrm{gm} \mathrm{cm}$ and $11000 \mathrm{rpm}$ for $50 \mathrm{gm} \mathrm{cm}$. A significant change in initial mechanical imbalance magnitude is predicted to change the synchronous response and the divergent speeds due to Morton Effect. Recall that SISRA requires some mechanical imbalance to obtain an orbit to begin iterative calculations. 


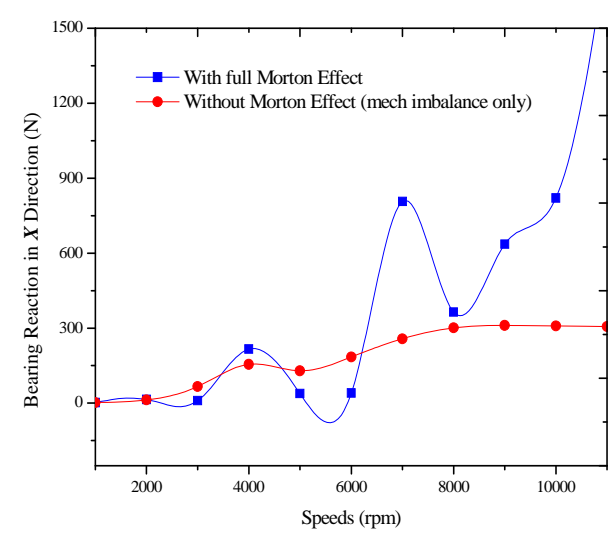

(a)

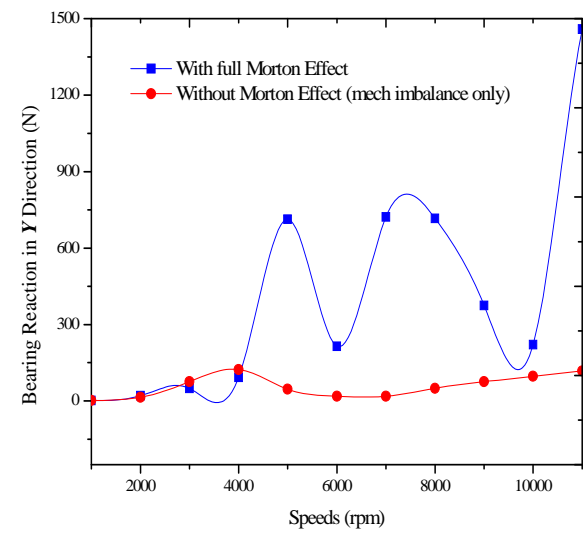

(b)

Figure 30. Bearing reaction versus $\omega$ with and without Morton Effect in $X$ and $Y$ planes

Figure 30(a) and 30(b) presents predicted bearing reaction magnitudes versus $\omega$

in both $X$ and $Y$ planes. Bearing reactions due to full Morton Effect and due to mechanical imbalance only are different beyond $3000 \mathrm{rpm}$. Bearing reaction at the divergent speed and at critical speeds due to Morton Effect are orders of magnitude greater with Morton Effect. The reactions are different in $X$ and $Y$ direction due to the orthotropic nature of loaded plain journal bearing.

\section{Influence of the Bearing $L / D$ Ratios}

This section examines the influence of changing $L / D$ from 0.35 to 0.5 . Increasing $L / D$ reduces bearing specific loading, which reduces its operating eccentricities. Table 
A2 gives the operating eccentricity, attitude angle, and viscosity along with differential temperature and phase angles.

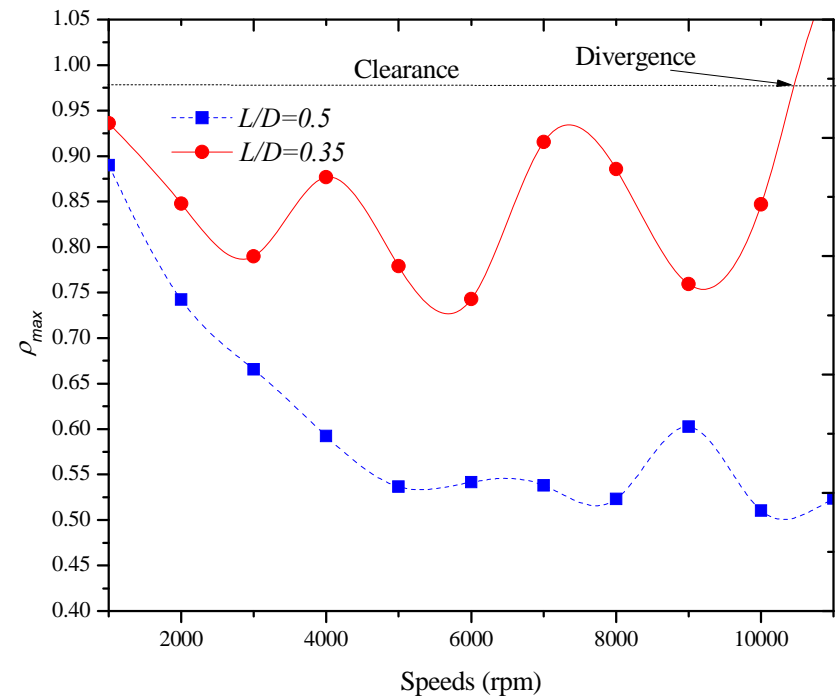

Figure 31. Morton Effect response- $\rho_{\max }$ versus $\omega$ for different $L / D$ ratios

Figure 31 presents $\rho_{\max }$ versus $\omega$ for two $L / D$ ratios with full Morton Effect and initial mechanical imbalance. For $L / D=0.5, \rho_{\max }$ does not cross the clearance circle for speeds up to $11000 \mathrm{rpm}$, indicating no divergent motion in this speed range. Operating static eccentricity with $L / D=0.5$ is less than $L / D=0.35$ as increasing the $L / D$ ratio reduces the unit load. SISRA predicts increasing $L / D$ ratio improves the synchronous response due to Morton Effect which conflicts with the experiences. Berot and Dourlens[31] and Schmeid et al.[21] solved Morton Effect instability problem by reducing $L / D$ for tilting-pad bearing. According to Schmeid et al.[21], "the thermal deflection per unit temperature rise in the bearing cross section is proportional to the 
width of bearing”. Both the configurations in Figure 32, have eccentric static eccentricity of the order of 0.4-0.7 in contrast of the turbo-expander model discussed by Schmeid et al. [19] that have $\varepsilon_{0} \sim 0.05$.

Increasing $L / D$ ratio, decreases the $\Delta T$ (as shown in Figure 32), which makes the difference in the synchronous response. The code never fails to converge for model with $L / D=0.5$.

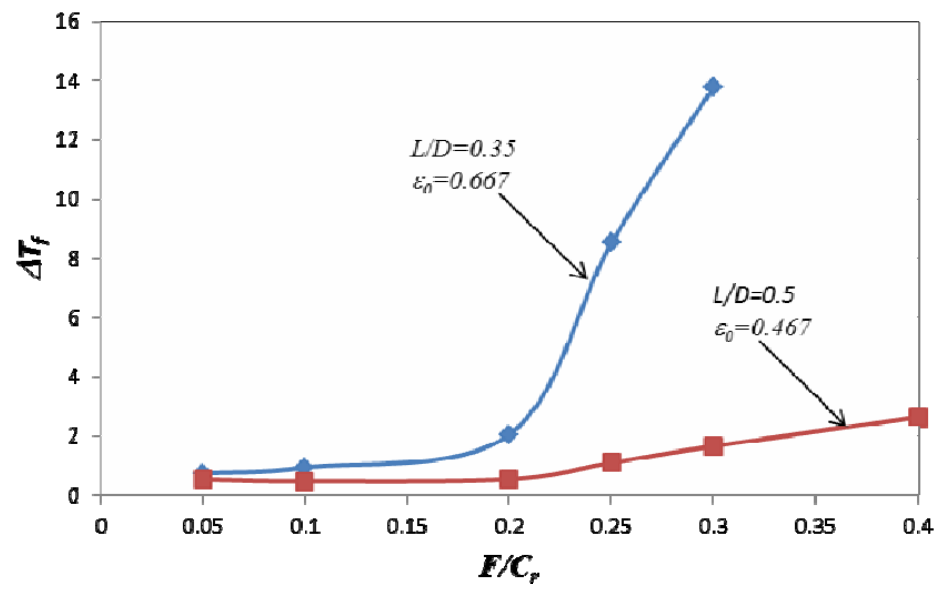

Figure 32. $\Delta T_{f}$ with $F / C r$ for $L / D=0.35$ and 0.5 at $7500 \mathrm{rpm}$

\section{Influence of the Bearing $C_{r} / R$ Ratios}

This section examines the influence of changing $C_{r} / R$ ratio from 0.002 to 0.001 on the Morton Effect characteristics. Only $C_{r} / R$ is changed in the original model. Table A3 gives the operating eccentricity, attitude angle, and viscosity along with differential temperature and phase angles. 
Figure 33 demonstrates that cutting $C_{r} / R$ from 0.002 to 0.001 causes the system to diverge due to Morton Effect after $7000 \mathrm{rpm}$. No recovery in response is predicted with increasing $\omega$.

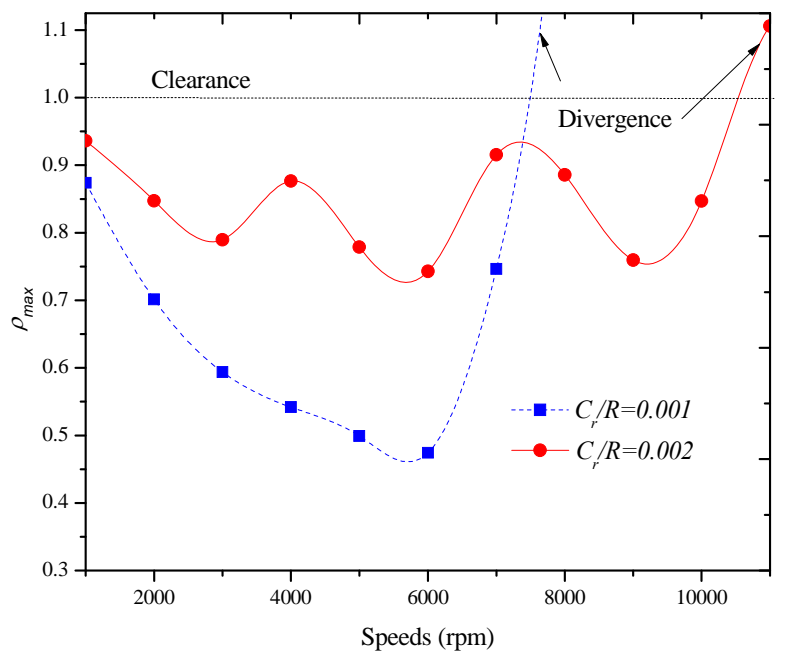

Figure 33. Morton Effect response $\rho_{\max }$ versus $\omega$ for different $\mathrm{Cr} / \mathrm{R}$ ratios

From Pinkus and Sternlicht [33], the power dissipated by a centered plain journal bearing is inversely proportional to the radial clearance. As shown in Figure 34, the differential temperature increases approximately by a factor of 2 for $C_{r} / R=0.001$ with respect to differential temperature for $C_{r} / R=0.002$. Notice, for the differential temperature increases more or less linearly for $C_{r} / R=0.001$ whereas for $C_{r} / R=0.002$, the differential temperature rise linearly with increasing amplitude up-to $F / C r=0.2$, beyond that temperature rise sharply with increase in orbit. This is because orbit amplitude approaches the clearance which causes higher shear viscous forces and larger differential temperature across the bearing. 


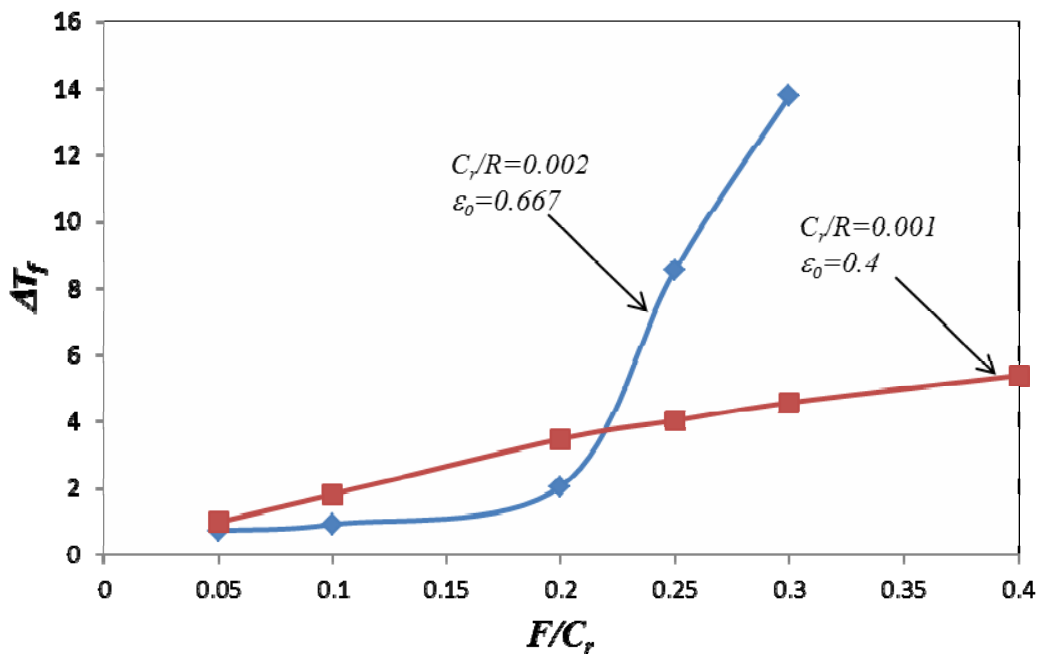

Figure 34. $\Delta T_{f}$ with $F / C r$ for $C r / R=0.001$ and 0.002 at $7500 \mathrm{rpm}$

Deliberately changing the clearances (either increase or decrease) has never been considered as an option to fix Morton Effect problem in the literature as changing the bearing clearance alters the load capacity, bearing stiffness, and damping significantly $[8]$.

\section{Influence of the Overhang Mass}

This section investigates the influence of overhung mass magnitudes on Morton Effect characteristics. The overhung masses of the original model were replaced with 50 $\mathrm{kg}$ in place of $20 \mathrm{~kg}$. Table A4 gives the operating eccentricity, attitude angle, and viscosity along with differential temperature and phase angles. 


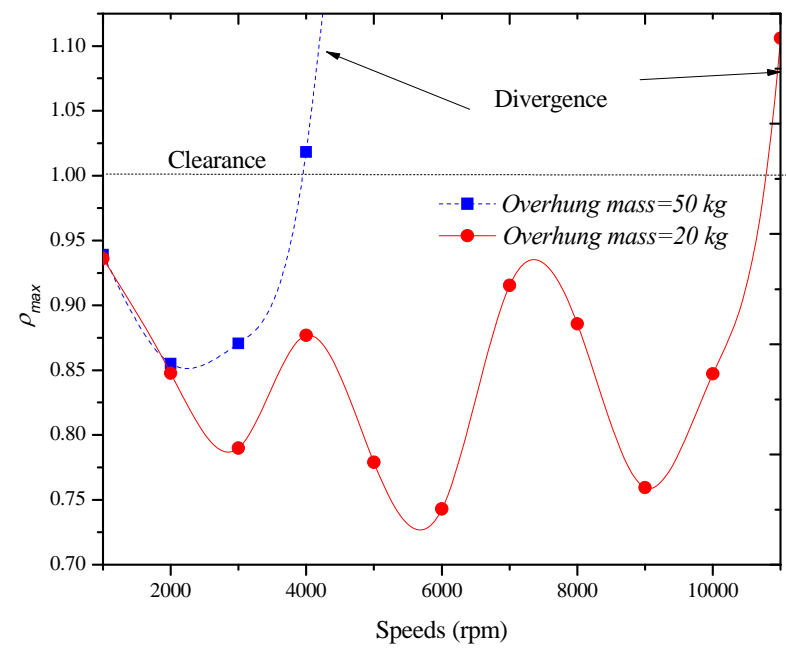

Figure 35. Morton Effect response $\rho_{\max }$ versus $\omega$ for different overhung masses

Figure 35 compares $\rho_{\max }$ versus $\omega$ for the two different overhung masses with full Morton Effect and initial mechanical imbalance. Synchronous response clearly increases due to an increase in overhung mass magnitude. Overhung mass increases both effective mass of the overhang (include concentrated overhung mass and mass of overhung part of rotor) and overhang effective length (refer Figure 1). The thermally induced mechanical imbalance is directly proportional to the product of an overhung mass and length. The increase in overhung mass is predicted to cause a sharp rise in response after $3000 \mathrm{rpm}$ making the system response divergent. This calculation confirms that heavier overhung masses at higher operation are more subject to Morton Effect [4]. Kocur and De Jongh [16] reduced the mass of overhang parts to fix Morton Effect. Corcoran et al. [34] present the only contrary result where increasing the coupling weight significantly, 
eliminated the Morton Effect problem. According to De Jongh [8], reducing the overhung mass is the best way to fix Morton Effect but not always feasible and practical.

Figure 36 shows $a / C_{r}$ versus $\omega$ for two different overhang masses. Notice, the sharp increasing in amplitude after 3000 rpm for overhung mass of $50 \mathrm{~kg}$.

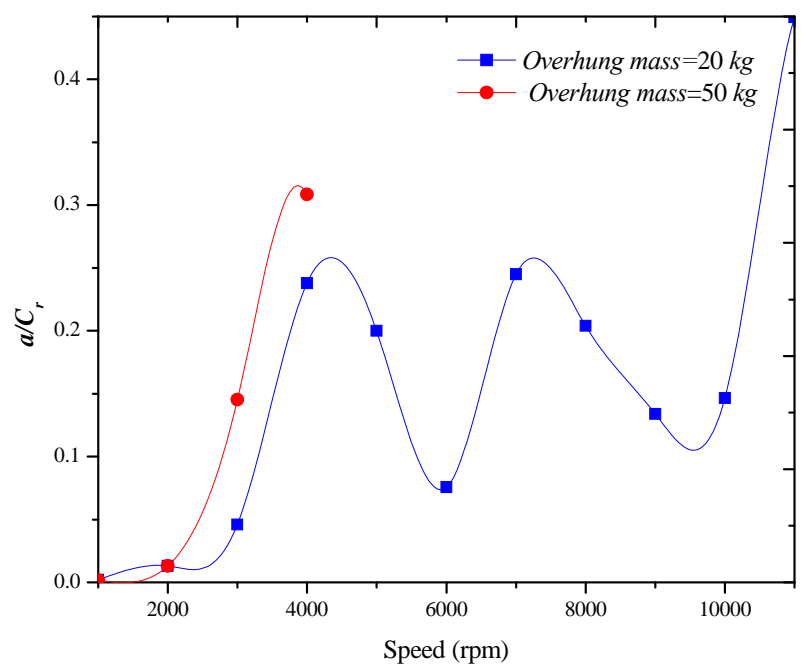

Figure 36. Morton Effect synchronous response $\boldsymbol{a} / \mathrm{Cr}$ versus $\omega$ for different overhung masses

\section{Influence of the Reduced Lubricant Viscosity}

This section investigates the influence of lubricant viscosity on the Morton Effect characteristics. The viscosity of Keogh and Morton's [11] model is given in Table 3 and the modified model have $70 \%$ of the original viscosity. The remaining parameters are the same. Table A5 gives the operating eccentricity, attitude angle, and viscosity along with differential temperature and phase angles. 


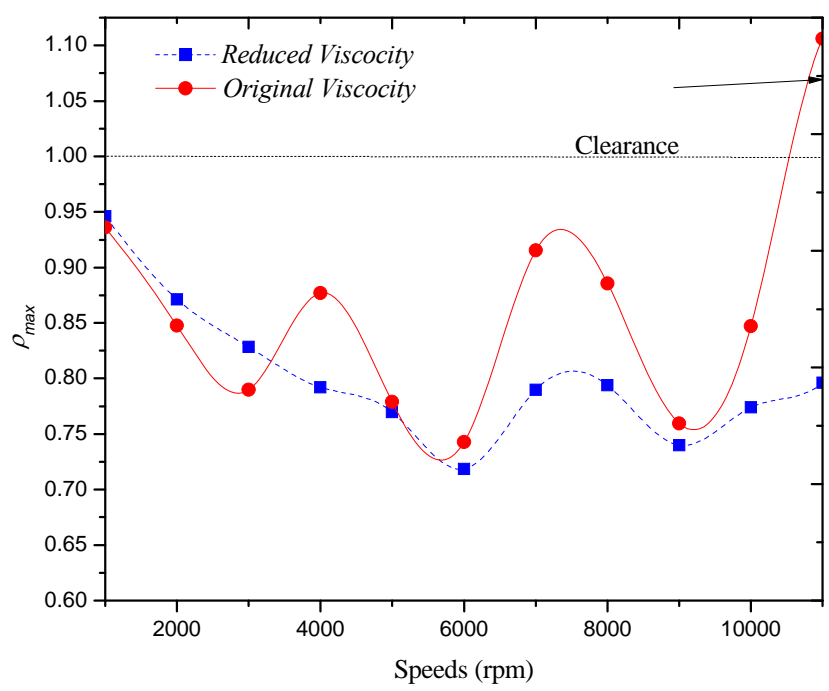

Figure 37. Morton Effect response $\rho_{\max }$ versus $\omega$ for different viscosities

Figure 37 presents the influence of reduced viscosity on Morton Effect response $\rho_{\max }$ versus $\omega$ with full Morton Effect and initial mechanical imbalance. Reduced viscosity increases the operating eccentricity but decreases the heat input into the shaft. No divergent motion is predicted for reduced viscosity within $12000 \mathrm{rpm}$. Schmeid et al. [21] and Marscher and Illis[12] (increased the supply temperature to reduce viscosity) made changes in lubricant viscosity to fix Morton Effect problem.

\section{MODEL-II, SCHMIED ET AL. (2008): TURBOEXPANDER}

For the second example, a double overhung turboexpander [21] supported on 5 pad, load-on pad, tilting-pad bearings is studied. The initial design of this unit exhibited diverging Morton effect behavior starting at a speed near 18,000 rpm. The first forward 
critical speed is $29000 \mathrm{rpm}$. This rotor shown in Figure 38, has a very stiff shaft, and its rotordynamic model is shown in Figure 39. The bearing details are given in Table 4. The first forward damped critical mode shape (Figure 40) has maximum deflection at the two impellers. Since differential heating in either bearing will cause the nearby impeller to go out of balance, the mode can be sensitive to differential heating at either bearings. The compressor-end impeller is the larger and heavier than the expander-end impeller. Vibration at the compressor end bearing exhibited a divergent spiral at 18,000 rpm as shown in Figure 41 [21].

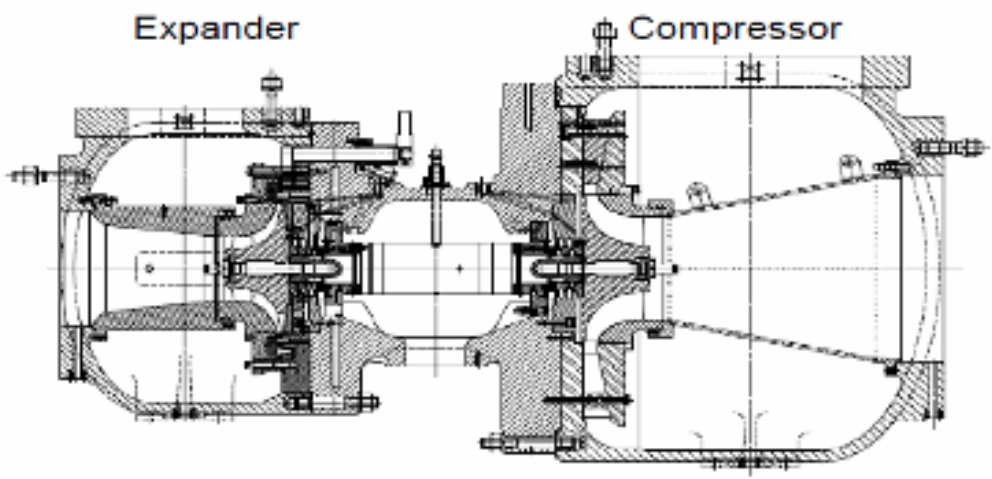

Figure 38. Real cross section of the turbo-expander [21]

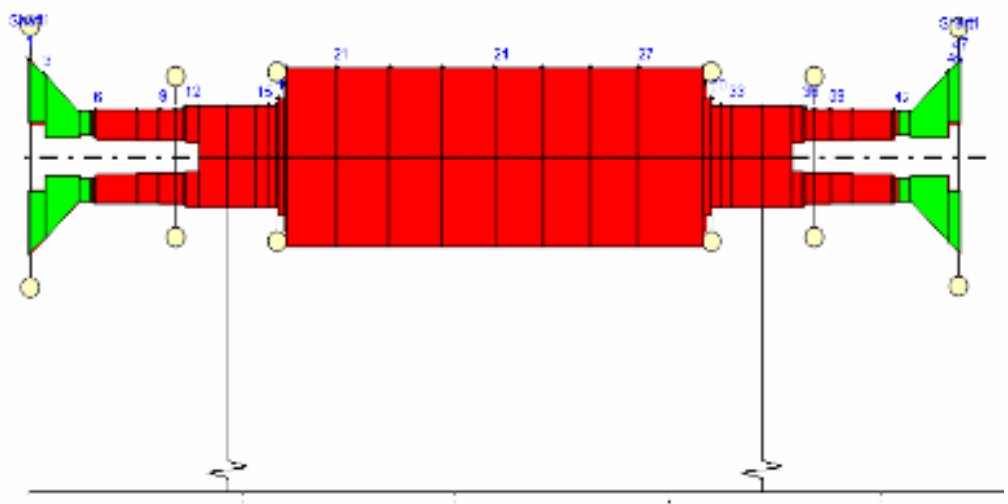

Figure 39. XLTRC ${ }^{2}$ model of the turbo-expander 
Table 4 Tilting pad bearing parameters [25]

\begin{tabular}{ll}
\hline Shaft diameter & $90 \mathrm{~mm}$ \\
Bearing outer diameter & $117 \mathrm{~mm}$ \\
Bearing axial length & $55 \mathrm{~mm}$ \\
Pad arc & $52^{\circ}$ \\
Pad pivot offset & 0.5 \\
Pad preload & 0.35 \\
Assembled diametric clearance & $185 \mathrm{~mm}$ \\
Oil inlet temperature & $43^{\circ} \mathrm{C}$ \\
Oil properties & ISO 46 \\
Oil supply flow rate & $23.6 \mathrm{liter} / \mathrm{min}$ \\
Bearing outer heat transfer coefficient & $50 \mathrm{~W} / \mathrm{m}^{2} / \mathrm{C}$ \\
\hline
\end{tabular}

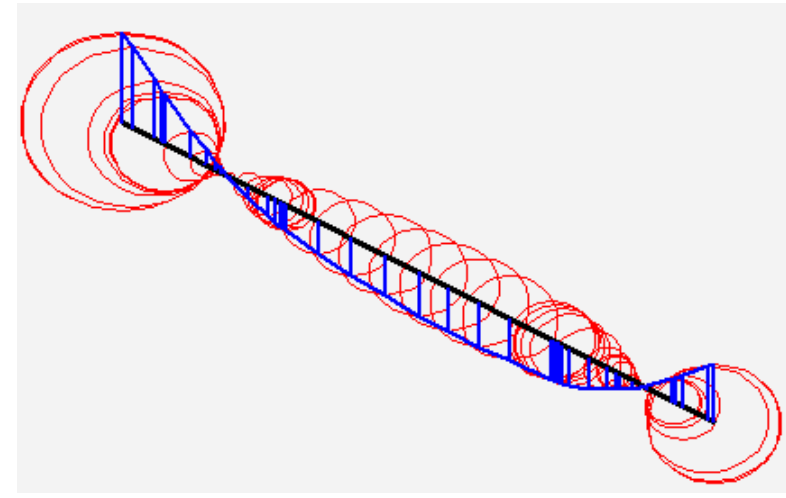

Figure 40. First forward damped critical mode shape of turbo-expander

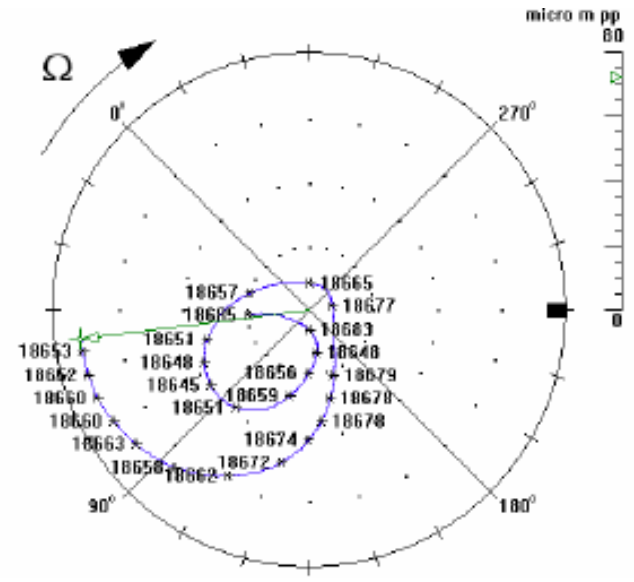

Figure 41. Unstable divergent behavior of spiral plot at $18000 \mathrm{rpm}$ [21] 
Table A6 gives the speed, eccentricities, attitude angle, radial clearances, viscosity, length and diameter of the bearing, calculated differential temperature and phase angles. Calculated differential temperature and phase lag angles are not available for tilting-pad bearings; hence, predictions will be used for plain journal bearing; whereas, eccentricities and attitude angle are calculated using a tilting-pad bearing code. The study seeks an idea of the machine response due to Morton Effect.

Figure 42 presents $\rho_{\max }$ versus $\omega$ for compressor and expander end bearings with full Morton Effect and initial mechanical imbalance. Compressor end bearing diverges at $13000 \mathrm{rpm}$, and expander end does not diverge until $15000 \mathrm{rpm}$, according to the SISRA predictions. Divergent speed due to Morton Effect is lower than the first forward critical speed (29000 rpm) for this model. Murphy and Lorenz [27] predicted Morton Effect instability from 21500 rpm onwards.

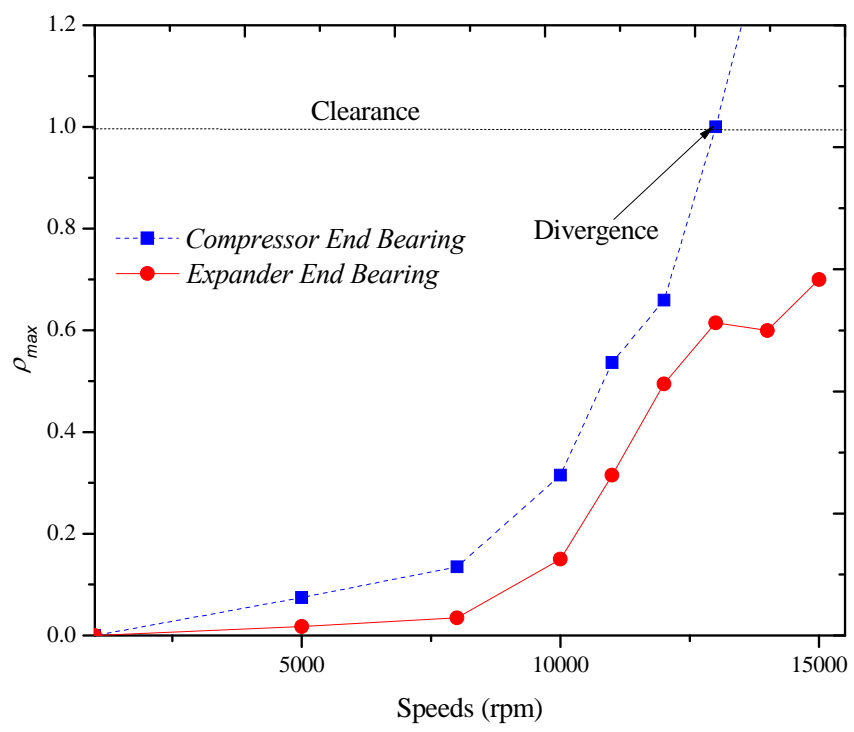

Figure 42. Morton Effect response $\rho_{\max }$ versus $\omega$ for the compressor and expander end bearings 


\section{CHAPTER IV}

\section{DISCUSSION AND CONCLUSIONS}

This thesis looks into the characteristics of the Morton Effect and also underlines

a new computational algorithm to analyze the synchronous response for the rotorbearing system with Morton Effect. This work also provides a method and a design tool to determine the synchronous response and divergent speed due to the Morton Effect. This chapter recalls the results and recommends open issues for further research. Based on the studies made on Morton Effect following conclusions can be made:

- $\quad$ Above a certain speed, synchronous response due to Morton Effect can be different that the synchronous response due to mechanical imbalance only.

- Mechanical imbalance magnitude has significant impact on the response due to Morton Effect. A very small amount of mechanical imbalance is required to begin calculations.

- Impacts of induced bent shaft moments are dominant.

- Output of the algorithm is very sensitive on the input differential temperature, phase and running speed.

- $\quad$ Operation in the critical speed range can enlarge Morton Effect response.

- $\quad$ Reducing the magnitude of overhung mass and lubricant viscosity are the most effective fixes for the Morton Effect problem. 
SISRA requires the input of differential temperature and phases from either test program or bearing codes. This is important because it calculates the synchronous response and also suggests the divergent speed with Morton Effect. All the currently used algorithms give only an onset speed of Morton Effect instability. This work also introduces a more direct and simplified approach to treat bent shaft excitation versus the traditional approach of obtaining bent-shaft excitation vectors using the rotor's free-free stiffness matrix. Convergence in a finite number of iterations of the synchronous response suggests a non-linear nature of the Morton Effect. This thesis casts the Morton Effect phenomenon as a synchronous response problem instead of a thermal stability problem.

\section{CAPABILITIES OF XLMORTON FEATURE IN XLTRC ${ }^{2}$}

The following are the features of Morton Effect subroutine in XLTRC ${ }^{2}$ :

- $\quad$ It can handle both forward and backward orbit temperature distribution.

- $\quad$ It can handle the non-linear nature of temperature differential with speed and amplitude.

- $\quad$ It can handle rotors with single and double overhang.

- $\quad$ It can handle any kind of bearing for which calculated or measured differential temperature and phase lag angles are provided.

- $\quad$ Code is setup to predict the synchronous response in the presence of the Morton Effect also in the presence of initial bent profile of the shaft. 


\section{DIRECTION FOR FUTURE RESEARCH}

SISRA needs to be validated with the more models. Lack of published data on differential temperature and phase lag angles of tilting-pad and other kind of bearings, makes a test program essentially need to be carried out to verify the predictive capability of the SISRA as well as the Dr. A. Palazzolo's bearing code [28]. Based on the results of the test program, the importance of eccentricities, preloading, rate of change of rotor speed and mechanical imbalance on the Morton Effect stability characteristics needs to be addressed. The stability of the orbits needs to be established. 


\section{NOMENCLATURE}

$a, b \quad$ Major, minor ellipse axes $m$

$C_{r} \quad$ Radial clearances $m$

D Diameter of bearing m

$\Delta T_{1} \quad$ Maximum effective differential temperature $\quad{ }^{0} \mathrm{C}$

$\Delta T_{f}, \Delta T_{b} \quad$ Maximum differential temperature of forward and $\quad{ }^{0} \mathrm{C}$

backward orbit

$F, B \quad$ Forward , backward orbit amplitude $m$

G $\quad$ Gain vector used by De Jongh and Morton [9]

$\boldsymbol{G}_{1} \quad$ Gain used by Keogh and Morton [14]

$G_{a T} \quad$ Total gain factor

$I_{a} \quad$ Moment of inertia of rotor $\mathrm{m}^{4}$

$\boldsymbol{I}_{O B} \quad$ Influence coefficient between the overhang and

bearing location

L Distance between overhang mass and bearing $\quad M$

L Length of bearing M

$l_{g r} \quad$ Distance between mass center and right bearing $\quad M$

$\begin{array}{lll}M_{c} & \text { Concentrated overhang mass } & \mathrm{kg}\end{array}$

$m_{g r} \quad$ Overhang mass of the right hand side of the rotor $\mathrm{kg}$

$\begin{array}{lll}M_{T} & \text { Bent shaft moment } & \mathrm{Nm}\end{array}$ 
$M T_{X 1}, M T_{Y 1} \quad$ Location rotor center in $X_{1}, Y_{1}$ coordinate system

$M Y_{x}, M T_{y^{\prime}} \quad$ Location rotor center in $x^{\prime}, y^{\prime}$ coordinate system

T Time $\quad S$

$\boldsymbol{T} \quad$ Complex thermal gain

$X, Y, Z \quad$ Stationary Coordinate System

$x, y, z \quad$ Rotor fixed coordinate system

$X_{1}, Y_{1}, Z \quad$ Stationary Coordinate System along static

eccentricity and attitude angle

$x_{T}, y_{T}, z \quad$ Rotor fixed coordinate system along the resultant hot

spot

$\alpha \quad$ Ellipse attitude angle

$\beta \quad$ Location of min film thickness in rotor fixed

coordinate system

$\beta_{T} \quad$ Bent slope angle due to temperature gradient

$\varepsilon_{0} \quad$ Eccentricity ratio

$\varepsilon_{f,} \varepsilon_{b} \quad$ Ratio of forward and backward amplitude to radial

clearance

$\gamma_{T} \quad$ Coefficient of thermal expansion

$C^{-1}$

$\varphi \quad$ Circumferential location on the journal

$\varphi_{T} \quad$ Location of maximum effective differential

temperature wrt to $x, y, z$ 


$\begin{array}{ll}\varphi_{T f}, \varphi_{T b} & \text { Phase angle between the hot spot and position of } \\ \text { minimum film thickness for forward and backward } & \text { orbit } \\ \mu & \text { Viscosity } \\ \theta & \text { Change in bend angle at the bearing } \\ \rho_{\text {max }} & \text { Maximum amplitude of rotor at the position of min } \\ & \text { film thickness } \\ \omega & \text { Running Speed } \\ \psi_{0} & \text { Attitude angle } \\ \text { SISRA } & \text { Successive Iterative Synchronous Response Algorithm }\end{array}$




\section{REFERENCES}

1. Nicholas, J. C., Gunter, E. J., and Allaire, P. E., 1976, "Effect of Residual Shaft Bow on Unbalance Response and Balancing of a Single Mass Flexible Rotor, Part 1: Unbalance Response,” ASME J. Eng. for Power, 98(2), pp.171-181.

2. Baldassarre, L., and Fontana, M., 2010, "Modelization of Rotor Bow During Hot Restart in Centrifugal Compressors," Proc. of $39^{\text {th }}$ Turbomachinery Symposium, College Station, TX.

3. Salamone, D. J., and Gunter, E. J., 1978, "Effects of Shaft Warp and Disk Skew on the Synchronous Unbalance Response of a Multimass Rotor in Fluid Film Bearings," Proc. of ASME Fluid Film Bearing and Rotor Bearing System Design and Optimization, New York, pp.79-87.

4. API 684 Standard, 2005, “API Standard Paragraphs Rotordynamic Tutorial: Lateral Critical Speeds, Unbalance Response, Stability, Train Torsionals, And Rotor Balancing,” Tech. Rep., Washington DC.

5. Newkirk, B. L., 1926, “Shaft Rubbing,” Mech. Eng., 48, pp. 830-832.

6. Dimorgonas, A.D., 1970, "Packing Rub Effect in Rotating Machinery," Ph.D. Dissertation, Rensselaer Polytechnic Institute, Troy, NY.

7. Phuttipongsit, A., 2007, “The Morton Effect and Light Rubs in Rotating Machinery,” Orbit Magazine, 27(1), pp. 44-51.

8. De Jongh, F. M., 2008, “The Synchronous Rotor Instability Phenomenon -Morton Effect,” Proc. of $27^{\text {th }}$ Turbomachinery Symposium, College Station, TX.

9. De Jongh, F. M., and Morton, P. G., 1996, "The Synchronous Instability of a Compressor Rotor due to Bearing Journal Differential Heating,” J. of Eng. for Gas Turbines and Power, 118(4), pp. 816-822.

10. Gomiciaga, R., and Keogh, P. S., 1999, “Orbit Induced Journal Temperature Variation in Hydrodynamic Bearings,” J. Trib., 121(1), pp. 77-84.

11. Keogh, P. S., and Morton, P. G., 1994, "Dynamic Nature of Rotor Thermal Bending due to Unsteady Lubricant Shearing within a Bearing,” Proc. of Royal Soc. London, Series A: Math. Phys. Sci. 445(1924), pp. 273-290. 
12. Marscher, W. D., and Illis, B., 2007, “Journal Bearing Morton Effect Cause of Cyclic Vibration in Compressors,” Trib. Trans., 50(1), pp. 104-113.

13. Morton, P. G., 2008, "Unstable Shaft Vibrations Arising from Thermal Effects due to Oil Shearing between Stationary and Rotating Elements," IMECHE Proc. of International Conference on Vibrations in Rotating Machinery, Exeter, England, C63/10/08.

14. Keogh, P. S., and Morton, P. G., 1993, “Journal Bearing Differential Heating Evaluation with Influence on Rotor Dynamic Behavior,” Proc. of Royal Soc. London, Series A: Math. Phys. Sci., 441(1913), pp. 527-548.

15. De Jongh, F. M., and Der Hoeven, P. V., 1998, “Application of Heat Sleeve Barrier to Synchronous Rotor Instability," Proc. of $27^{\text {th }}$ Turbomachinery Symposium, College Station, TX, pp. 17-26.

16. Kocur, J. A., and De Jongh, F. M., 2000, “Thermal Instability in Gas Compressors,” Proc. of AVPG $14^{\text {th }}$ International Gas Convention, Caracus, Venezuela.

17. Kellenberger, W., 1980, "Spiral Vibrations due to the Seal Rings in Turbogenerators Thermally Induced Interaction between Rotor and Stator," ASME J. of Mech. Design, 102(1), pp. 177-184.

18. Childs, D. W., 2001, “A Note on Kellenberger's Model for Spiral Vibrations,” ASME J. of Vib. Acoust., 123(3), pp. 405-408.

19. Schmied, J., 1987, “Spiral Vibrations of Rotors,” Proc. of 11th Biennal ASME Design Engineering Div. Conference, Vibration and Noise, Rotating Machinery Dynamics, Boston, MA, pp. 449-456.

20. Eckert, L., and Schmied, J., 2008, "Spiral Vibration of a Turbogenerator Set: Case History, Stability Analysis, Measurements and Operational Experience,” ASME J. Eng. for Gas Turbine and Power, 130(1), pp.1-10.

21. Schmied, J., Pozivil, J., and Walch, J., 2008, “Hot Spots in Turboexpander Bearings: Case History, Stability Analysis, Measurements and Operational Experience,” Proc. of ASME IGTI Turboexpo 2008, Berlin, Germany, pp.1267-1277.

22. Liebich, R., and Gasch, R., 1996, "Spiral Vibrations - Modal Treatment of a RotorRub Problem based on Coupled Structural/Thermal Equations,” IMECHE Trans., 6, pp.405-414.

23. Lund, J. W., 1966, "Self-Excited, Stationary Whirl Orbits of a Journal in a Sleeve Bearing,” Ph.D. Dissertation, Rensselaer Polytechnic Institute, Troy, NY. 
24. Balbahadur, A. C., and Kirk, R. G., 2004, "Part 1-Theoretical Model for a Synchronous Thermal Instability Operating in Overhung Rotors,” Int. J. Rotating Mach., 10(6), pp. 469-475.

25. Murphy, B., and Lorenz, J., 2009, "Simplified Morton Effect Analysis for Synchronous Spiral Instability,” Proc. of PWR2009, Albuquerque, NM, pp. 21-23.

26. Strong, W. F., Faulkner, H. B., and Kirk, R. G., 1997, "Thermally Induced Synchronous Instability of a Radial Overhung Turbine, Part-1,” Proc. of Design Engineering Tech. Conf. ASME, Sacramento, CA, DETC/VIB-4063.

27. Berot, F., and Dourlens, H., 2000, “On Instability of Overhung Centrifugal Compressors,” Proc. of ASME IGTI Turboexpo 2000, Indianapolis, IN, 99-GT-202.

28. Palazzolo, A., and Lu, Z., 2010, "Matlab Code for Plain Journal Bearing Temperature and Phase Predictions,” Private Correspondence.

29. Palazzolo, A., 2005, "Theory for Fixed Pad Hydrodynamic Journal Bearings, Intelligent Rotor Bearing Design Tool,” Dynatech Report, TAMU Project 3252525070 (Report \# 9).

30. Gadangi, R., K., 1995, “Transient Rotordynamics with Flexible Shaft and Flexible Nonlinear Hydrodynamic Journal Bearings including Thermal Effects,” Ph.D. Dissertation, Texas A\&M University, College Station, TX.

31. Kim, J., 1993, “Thermoelastohydrodynamic Tilting Pad Journal Bearing Simulation and Application to Rotor Bearing Model," Ph.D. Dissertation, Texas A\&M University, College Station, TX.

32. Balbahadur, A. C., and Kirk, R. G., 2004, "Part 2-Case Studies for a Synchronous Thermal Instability Operating in Overhung Rotors,” Int. J. Rotating Mach., 10(6), pp. 477-487.

33. Pinkus, O., and Sternlicht, B., 1961, Theory of Hydrodynamic Lubrication, $2^{\text {nd }}$ Edition, McGraw Hill, New York.

34. Corcoran, J. P., Rea, H., Cornejo, G. A., Leonhard, M. L., 1997, “Discovering, the Hard Way, How a High Performance Coupling Influenced the Critical Speeds and Bearing Loading of an Overhung Radial Compressor-A Case History," Proc. of $17^{\text {th }}$ Turbomachinery Symposium, College Station, TX, pp. 67-78. 
APPENDIX A

CALCULATED DIFFERENTIAL TEMPERATURE AND PHASE ANGLES FOR PLAIN JOURNAL BEARING AT VARIOUS SPEEDS

Table A1 Calculated differential temperature and phase angles for $L=0.035 \mathrm{~m}, D=0.1 \mathrm{~m}, C_{r}=100 \mu \mathrm{m}$

\begin{tabular}{|c|c|c|c|c|c|c|c|c|c|}
\hline $\begin{array}{l}\text { Speeds } \\
\text { (rpm) }\end{array}$ & $\varepsilon_{0}$ & $\begin{array}{l}\mu \\
(\mathrm{Pa}-\mathrm{s})\end{array}$ & $\begin{array}{l}\psi_{0} \\
(0)\end{array}$ & $F / C_{r}$ & $\begin{array}{l}\Delta T_{f} \\
\left({ }^{\circ} \mathrm{C}\right)\end{array}$ & $\begin{array}{l}\varphi_{T f} \\
\left(^{\circ}\right)\end{array}$ & $B / C_{r}$ & $\begin{array}{l}\Delta T_{b} \\
\left({ }^{\circ} \mathrm{C}\right)\end{array}$ & $\begin{array}{l}\varphi_{T b} \\
\left(^{\circ}\right)\end{array}$ \\
\hline \multirow{4}{*}{5000} & \multirow{4}{*}{0.709} & \multirow{4}{*}{0.091} & \multirow{4}{*}{38.0} & 0.05 & 0.6328 & 48 & 0.05 & 0.6437 & -48 \\
\hline & & & & 0.10 & 0.9121 & 36 & 0.10 & 0.9589 & -36 \\
\hline & & & & 0.20 & 2.1881 & 24 & 0.20 & 2.1879 & -24 \\
\hline & & & & 0.25 & 18.345 & 24 & 0.25 & 18.56 & -24 \\
\hline \multirow{5}{*}{7500} & \multirow{5}{*}{0.667} & \multirow{5}{*}{0.081} & \multirow{5}{*}{41.2} & 0.05 & 0.7361 & 72 & 0.05 & 0.7898 & -84 \\
\hline & & & & 0.10 & 0.9314 & 36 & 0.10 & 0.9058 & -48 \\
\hline & & & & 0.20 & 2.0425 & 24 & 0.20 & 2.1279 & -24 \\
\hline & & & & 0.25 & 8.5327 & 12 & 0.25 & 7.8965 & -12 \\
\hline & & & & 0.30 & 13.785 & 36 & 0.30 & 12.6534 & -54 \\
\hline \multirow{5}{*}{9000} & \multirow{5}{*}{0.655} & \multirow{5}{*}{0.073} & \multirow{5}{*}{42.2} & 0.05 & 0.7855 & 84 & 0.05 & 0.7884 & -72 \\
\hline & & & & 0.10 & 0.9136 & 48 & 0.10 & 0.8841 & -60 \\
\hline & & & & 0.20 & 1.7729 & 24 & 0.20 & 1.7673 & -24 \\
\hline & & & & 0.25 & 8.3993 & 12 & 0.25 & 8.3612 & -12 \\
\hline & & & & 0.30 & 12.7643 & 24 & 0.30 & 13.564 & -36 \\
\hline
\end{tabular}


Table A2 Calculated differential temperature and phase angles for $L=0.05 m, D=0.1 m, C_{r}=100 \mu m$

\begin{tabular}{|c|c|c|c|c|c|c|c|c|c|}
\hline $\begin{array}{l}\text { Speeds } \\
\text { (rpm) }\end{array}$ & $\varepsilon_{0}$ & $\begin{array}{l}\mu \\
\text { (Pa-s) }\end{array}$ & $\begin{array}{l}\psi_{0} \\
\left({ }^{\circ}\right)\end{array}$ & $F / C_{r}$ & $\begin{array}{l}\Delta T_{f} \\
\left({ }^{\circ} \mathrm{C}\right)\end{array}$ & $\begin{array}{l}\varphi_{I f} \\
\left(^{\circ}\right)\end{array}$ & $B / C_{r}$ & $\begin{array}{l}\Delta T_{b} \\
\left({ }^{\circ} \mathrm{C}\right)\end{array}$ & $\begin{array}{l}\varphi_{T b} \\
\left({ }^{\circ}\right)\end{array}$ \\
\hline \multirow{5}{*}{5000} & \multirow{5}{*}{0.524} & \multirow{5}{*}{0.091} & \multirow{5}{*}{51.9} & 0.05 & 0.37 & 60.00 & 0.05 & 0.2971 & -48 \\
\hline & & & & 0.10 & 0.3679 & 36 & 0.10 & 0.4034 & -48 \\
\hline & & & & 0.20 & 0.632 & 36 & 0.20 & 0.6565 & -24 \\
\hline & & & & 0.30 & 1.9543 & 12 & 0.30 & 1.986 & -24 \\
\hline & & & & 0.40 & 3.394 & 24 & 0.40 & 3.356 & -12 \\
\hline \multirow{5}{*}{7500} & \multirow{5}{*}{0.467} & \multirow{5}{*}{0.080} & \multirow{5}{*}{56.1} & 0.05 & 0.5223 & 96 & 0.05 & 0.5018 & -84 \\
\hline & & & & 0.10 & 0.4652 & 108 & 0.10 & 0.5287 & -96 \\
\hline & & & & 0.20 & 0.5369 & 48 & 0.20 & 0.4774 & -72 \\
\hline & & & & 0.30 & 1.6543 & 24 & 0.30 & 1.765 & -12 \\
\hline & & & & 0.40 & 2.6311 & 12 & 0.40 & 2.5412 & -36 \\
\hline \multirow{5}{*}{9000} & \multirow{5}{*}{0.453} & \multirow{5}{*}{0.071} & \multirow{5}{*}{57.1} & 0.05 & 0.65 & 108 & 0.05 & 0.5885 & -96 \\
\hline & & & & 0.10 & 0.608 & 108 & 0.10 & 0.606 & -108 \\
\hline & & & & 0.20 & 0.6511 & 96 & 0.20 & 0.6825 & -108 \\
\hline & & & & 0.30 & 1.812 & 36 & 0.30 & 1.876 & -12 \\
\hline & & & & 0.40 & 2.356 & 12 & 0.40 & 2.493 & -24 \\
\hline
\end{tabular}

Table A3 Calculated differential temperature and phase angles for $L=0.035 \mathrm{~m}, D=0.1 \mathrm{~m}, C_{r}=50 \mu \mathrm{m}$

\begin{tabular}{llllllllll}
\hline $\begin{array}{l}\text { Speeds } \\
(\mathrm{rpm})\end{array}$ & $\varepsilon_{0}$ & $\begin{array}{l}\mu \\
(\mathrm{Pa}-\mathrm{s})\end{array}$ & $\begin{array}{c}\psi_{0} \\
\left({ }^{\circ}\right)\end{array}$ & $F / C_{r}$ & $\begin{array}{l}\Delta T_{f} \\
\left({ }^{\circ} \mathrm{C}\right)\end{array}$ & $\begin{array}{l}\varphi_{T f} \\
\left({ }^{\circ}\right)\end{array}$ & $B / C_{r}$ & $\begin{array}{l}\Delta T_{b} \\
\left({ }^{\circ} \mathrm{C}\right)\end{array}$ & $\begin{array}{l}\varphi_{T b} \\
\left({ }^{\circ}\right)\end{array}$ \\
\hline & & & & 0.05 & 0.6561 & 36 & 0.05 & 0.576 & -108 \\
& & & & 0.10 & 1.0437 & 36 & 0.10 & 1.0187 & -24 \\
5000 & 0.459 & 0.091 & 56.7 & 0.20 & 1.935 & 24 & 0.20 & 2.0162 & -36 \\
& & & & 0.30 & 3.141 & 24 & 0.30 & 3.245 & -24 \\
& & & & 0.40 & 4.368 & 24 & 0.40 & 4.982 & -24 \\
\hline & & & & 0.05 & 0.9953 & 36 & 0.05 & 0.9916 & -36 \\
7500 & 0.400 & \multirow{2}{*}{0.080} & \multirow{2}{*}{60.94} & 0.10 & 1.8152 & 36 & 0.10 & 1.7824 & -24 \\
& & & & 0.30 & 3.4613 & 24 & 0.20 & 3.508 & -24 \\
& & & & 0.40 & 5.367 & 24 & 0.30 & 4.876 & -24 \\
& & & & 0.05 & 1.1456 & 36 & 0.40 & 5.479 & -24 \\
\hline & & & & 0.10 & 2.1215 & 36 & 0.10 & 1.1957 & -36 \\
9000 & 0.385 & 0.071 & \multirow{2}{*}{62.03} & 0.20 & 4.0371 & 24 & 0.20 & 4.0623 & -36 \\
& & & & 0.30 & 6.7841 & 24 & 0.30 & 6.4321 & -24 \\
& & & & 0.40 & 8.3421 & 24 & 0.40 & 8.241 & -24 \\
\hline
\end{tabular}


Table A4 Calculated differential temperature and phase angles for $L=0.035 m, D=0.1 m, C_{r}=100 \mu m$ with overhung mass of $50 \mathrm{~kg}$

\begin{tabular}{llllllllll}
\hline $\begin{array}{l}\text { Speeds } \\
(\mathrm{rpm})\end{array}$ & $\varepsilon_{0}$ & $\begin{array}{l}\mu \\
(\mathrm{Pa}-\mathrm{s})\end{array}$ & $\begin{array}{c}\psi_{0} \\
\left({ }^{0}\right)\end{array}$ & $F / C_{r}$ & $\begin{array}{l}\Delta T_{f} \\
\left({ }^{\circ} \mathrm{C}\right)\end{array}$ & $\begin{array}{l}\varphi_{T f} \\
\left({ }^{\circ}\right)\end{array}$ & $B / C_{r}$ & $\begin{array}{l}\Delta T_{b} \\
\left({ }^{\circ} \mathrm{C}\right)\end{array}$ & $\begin{array}{l}\varphi_{T b} \\
\left({ }^{\circ}\right)\end{array}$ \\
\hline \multirow{3}{*}{5000} & \multirow{2}{*}{0.73} & \multirow{2}{*}{0.091} & \multirow{2}{*}{36.57} & 0.10 & 1.0437 & 36 & 0.10 & 1.0187 & -24 \\
& & & & 0.20 & 1.935 & 24 & 0.20 & 2.0162 & -36 \\
& & & & 0.25 & 9.865 & 24 & 0.25 & 9.564 & -24 \\
\hline \multirow{3}{*}{7500} & \multirow{2}{*}{0.69} & \multirow{2}{*}{0.080} & \multirow{2}{*}{39.48} & 0.10 & 1.12235 & 48 & 0.10 & 1.1028 & -36 \\
& & & & 0.20 & 3.2789 & 24 & 0.20 & 2.83 & -12 \\
& & & & 0.30 & 13.55 & 24 & 0.30 & 13.568 & -24 \\
\hline \multirow{3}{*}{9000} & \multirow{2}{*}{0.68} & \multirow{2}{*}{0.071} & \multirow{2}{*}{40.26} & 0.10 & 1.0724 & 60 & 0.10 & 1.0787 & -48 \\
& & & & 0.20 & 2.6941 & 24 & 0.20 & 2.5313 & -24 \\
& & & & 0.30 & 17.17 & 24 & 0.30 & 15.76 & -24 \\
\hline
\end{tabular}

Table A5 Calculated differential temperature and phase angles for $L=0.035 m, D=0.1 m, C_{r}=100 \mu m$ with reduced viscosity

\begin{tabular}{llllllllll}
\hline $\begin{array}{l}\text { Speeds } \\
(\mathrm{rpm})\end{array}$ & $\varepsilon_{0}$ & $\begin{array}{l}\mu \\
(\mathrm{Pa}-\mathrm{s})\end{array}$ & $\begin{array}{c}\psi_{0} \\
\left({ }^{0}\right)\end{array}$ & $F / C_{r}$ & $\begin{array}{l}\Delta T_{f} \\
\left({ }^{\circ} \mathrm{C}\right)\end{array}$ & $\begin{array}{l}\varphi_{T f} \\
\left({ }^{\circ}\right)\end{array}$ & $B / C_{r}$ & $\begin{array}{l}\Delta T_{b} \\
\left({ }^{\circ} \mathrm{C}\right)\end{array}$ & $\begin{array}{l}\varphi_{T b} \\
\left({ }^{\circ}\right)\end{array}$ \\
\hline \multirow{3}{*}{5000} & \multirow{2}{*}{0.749} & \multirow{2}{*}{0.063} & \multirow{2}{*}{34.7903} & 0.10 & 0.8677 & 24 & 0.10 & 0.8571 & -24 \\
& & & & 0.20 & 2.5667 & 24 & 0.20 & 2.5456 & -24 \\
& & & & 0.24 & 4.664 & 24 & 0.24 & 6.8675 & -48 \\
\hline \multirow{3}{*}{7500} & \multirow{2}{*}{0.714} & \multirow{2}{*}{0.056} & \multirow{2}{*}{37.602} & 0.10 & 0.9696 & 36 & 0.10 & 0.9598 & -36 \\
& & & & 0.20 & 2.7047 & 12 & 0.20 & 2.8241 & -12 \\
& & & & 0.25 & 5.738 & 24 & 0.25 & 5.7065 & -24 \\
\hline \multirow{3}{*}{9000} & \multirow{2}{*}{0.704} & \multirow{2}{*}{0.05} & \multirow{2}{*}{38.3903} & 0.10 & 0.935373 & 48 & 0.10 & 0.9272 & -48 \\
& & & & 0.20 & 2.6173 & 12 & 0.20 & 2.5879 & -12 \\
& & & & 0.25 & 4.664 & 12 & 0.25 & 4.564 & -24 \\
\hline
\end{tabular}


Table A6 Calculated differential temperature and phase angles for $L=0.055 m, D=0.09 m, C_{r}=92.5 \mu m$

\begin{tabular}{|c|c|c|c|c|c|c|c|c|c|}
\hline $\begin{array}{l}\text { Speeds } \\
\text { (rpm) }\end{array}$ & $\varepsilon_{0}$ & $\begin{array}{l}\mu \\
\text { (Pa-s) }\end{array}$ & $\begin{array}{l}\psi_{0} \\
\left(0^{0}\right.\end{array}$ & $F / C_{r}$ & $\begin{array}{l}\Delta T_{f} \\
\left({ }^{\circ} \mathrm{C}\right)\end{array}$ & $\begin{array}{l}\varphi_{T f} \\
\left({ }^{\circ}\right)\end{array}$ & $B / C_{r}$ & $\begin{array}{l}\Delta T_{b} \\
\left({ }^{\circ} \mathrm{C}\right)\end{array}$ & $\begin{array}{l}\varphi_{T b} \\
\left(^{\circ}\right)\end{array}$ \\
\hline \multirow{6}{*}{5000} & \multirow{6}{*}{0.0635} & \multirow{6}{*}{0.035} & \multirow{6}{*}{0} & 0.05 & 0.1605 & 24 & 0.05 & 0.2069 & -48 \\
\hline & & & & 0.10 & 0.2362 & 48 & 0.10 & 0.2314 & -36 \\
\hline & & & & 0.20 & 0.1469 & 24 & 0.20 & 0.071 & -156 \\
\hline & & & & 0.40 & 0.0711 & 36 & 0.40 & 0.1083 & -48 \\
\hline & & & & 0.60 & 0.1505 & 36 & 0.60 & 0.1642 & -36 \\
\hline & & & & 0.80 & 0.5189 & 24 & 0.80 & 0.5326 & -24 \\
\hline \multirow{6}{*}{10000} & \multirow{6}{*}{0.0491} & \multirow{6}{*}{0.035} & \multirow{6}{*}{0} & 0.05 & 0.7629 & 24 & 0.05 & 0.7069 & -24 \\
\hline & & & & 0.10 & 0.6396 & 24 & 0.10 & 0.66 & -24 \\
\hline & & & & 0.20 & 0.4149 & 48 & 0.20 & 0.4069 & -48 \\
\hline & & & & 0.40 & 0.2642 & 108 & 0.40 & 0.2741 & -96 \\
\hline & & & & 0.60 & 0.4241 & 84 & 0.60 & 0.4000 & -84 \\
\hline & & & & 0.80 & 1.1781 & 36 & 0.80 & 1.1065 & -36 \\
\hline \multirow{6}{*}{15000} & \multirow{6}{*}{0.0434} & \multirow{6}{*}{0.035} & \multirow{6}{*}{0} & 0.05 & 1.9067 & 24 & 0.05 & 1.8269 & -24 \\
\hline & & & & 0.10 & 1.667 & 24 & 0.10 & 1.6798 & -24 \\
\hline & & & & 0.20 & 0.5818 & 60 & 0.20 & 0.6357 & -48 \\
\hline & & & & 0.40 & 0.6617 & 132 & 0.40 & 0.6612 & -132 \\
\hline & & & & 0.60 & 0.7665 & 108 & 0.60 & 0.8449 & -108 \\
\hline & & & & 0.80 & 1.5315 & 36 & 0.80 & 1.4957 & -36 \\
\hline
\end{tabular}




\section{VITA}

Name: $\quad$ Rohit Saha

Address: Department of Mechanical Engineering, 3123 TAMU, College Station, TX 77843-3123

Email: saha.rohit@gmail.com

Interests: Numerical Modeling, Rotordynamics

Education: B.Tech. in civil engineering, Institute of Technology, Banaras Hindu University, India, May 2008

M.S. in mechanical engineering, Texas A\&M University, College Station, Dec 2010. 